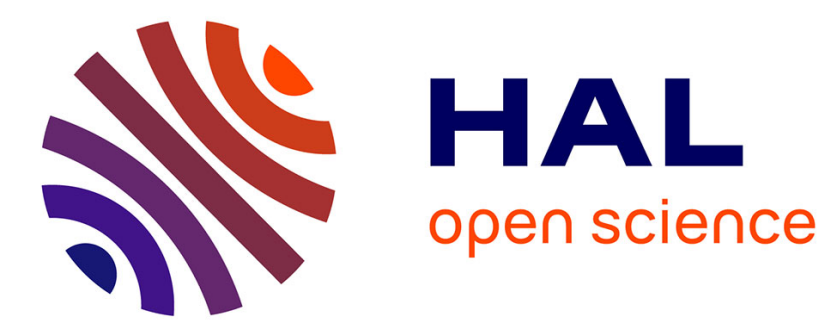

\title{
Recent advances in ice templating: from biomimetic composites to cell culture scaffolds and tissue engineering
}

Kankan Qin, Cleo Parisi, Francisco M Fernandes

\section{To cite this version:}

Kankan Qin, Cleo Parisi, Francisco M Fernandes. Recent advances in ice templating: from biomimetic composites to cell culture scaffolds and tissue engineering. Journal of materials chemistry B, 2021, 9 (4), pp.889-907. 10.1039/D0TB02506B . hal-03263326

\section{HAL Id: hal-03263326 \\ https: / hal.sorbonne-universite.fr/hal-03263326}

Submitted on 17 Jun 2021

HAL is a multi-disciplinary open access archive for the deposit and dissemination of scientific research documents, whether they are published or not. The documents may come from teaching and research institutions in France or abroad, or from public or private research centers.
L'archive ouverte pluridisciplinaire HAL, est destinée au dépôt et à la diffusion de documents scientifiques de niveau recherche, publiés ou non, émanant des établissements d'enseignement et de recherche français ou étrangers, des laboratoires publics ou privés. 


\title{
Recent advances in ice templating: from biomimetic composites to cell culture scaffolds and tissue engineering
}

\author{
Kankan Qin, Cleo Parisi and Francisco M. Fernandes* \\ Laboratoire de Chimie de la Matière Condensée de Paris, Sorbonne Université, 4 Place Jussieu, 75005 \\ Paris, France \\ *Corresponding author : francisco.fernandes@sorbonne-universite.fr
}

\begin{abstract}
Ice templating - or freeze casting - has flourished in multiple domains as a straightforward process to shape solutions and particle suspensions into macroporous materials. Longtime used as a process to shape colloidal suspensions into lightweight ceramics, the use of ice templating has evolved to fabricate materials that mimic the architecture of biological tissues such as nacre and bone. Recently, the technique has been used to shape biopolymers for cell culture systems and tissue engineering applications and eventually to allow the fabrication of biomaterials containing living cells. Here we review how ice templating has progressed to cope with intrinsically labile biological matter and how these advances may shape the future 3D cell culture, tissue engineering and ultimately, cryobiology.
\end{abstract}




\section{From porous ceramics to biomaterials fabrication}

Ice templating, also called freeze casting or ice segregation induced self-assembly, is a straightforward processing technique for the elaboration of macroporous materials. ${ }^{1,2}$ Beyond porosity, materials elaborated via ice templating display a diversity of other properties such as high specific elastic modulus $^{3}$, increased toughness ${ }^{4,5}$ or efficient insulating properties ${ }^{6}$ that can be easily tailored by adjusting the process parameters. Ice templated materials have thus attracted significant attention in the last decades as they are expected to find application in a wide variety of domains such as structural ceramics ${ }^{7}$, energy storage devices $^{8-10}$, sensors ${ }^{11,12}$ and, more recently, 3D cell culture ${ }^{13}$, tissue engineering ${ }^{14-16}$ or cellencapsulation systems ${ }^{17,18}$. The technique's underlying principle is remarkably simple. Starting with a suspension or a solution, and upon application of a temperature gradient that reaches values below the solvent freezing temperature, the sample freezes progressively and suspended particles and/or solutes are segregated into the interstitial zones defined by the solidified solvent. Different setups can be used to attain this thermal control over the sample and thus to promote the directional growth of ice. Figure 1 depicts three of the most common experimental setups used in ice templating. Removing the solvent without disturbing the interstitial zones reveals the materials' macroporosity, one of the central attributes of the materials obtained by ice templating. If the thermal gradient applied during freezing is well defined, then the solvent solidification will - under most circumstances - generate a freezing front that follows the local thermal field. While many solvents such as camphene ${ }^{19}$, tert-butyl alcohol ${ }^{20}$ or liquid $\mathrm{CO}_{2}{ }^{21}$ may be used to produce materials by ice templating, water is by far the most commonly used, and the most relevant in the context of biomaterials fabrication. ${ }^{22}$ Here we will limit the discussion to the latter and we will refer, from this point onwards, to the technique as ice templating. 
A
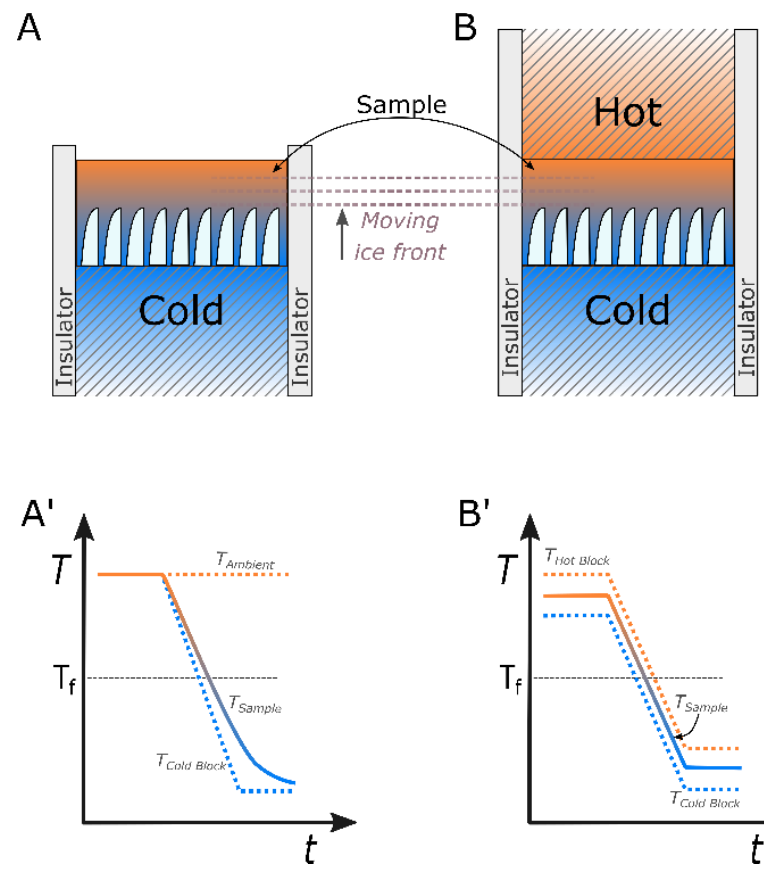

$\mathrm{B}^{\prime}$

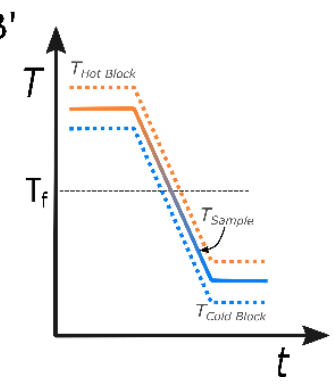

C
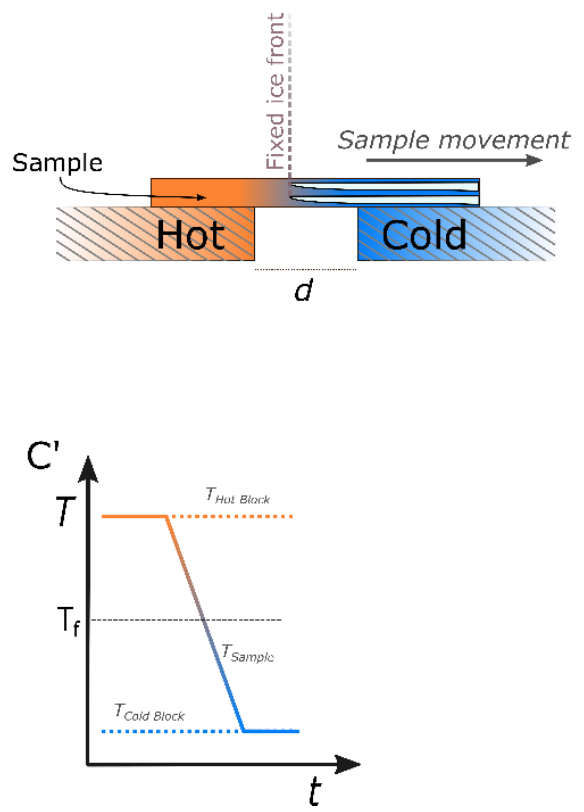

Figure 1. The thermal gradient necessary to promote unidirectional growth of ice crystals can be obtained using different setups. A) Single thermal element freezing setup, B) Double thermal element freezing setup and C) Directional freezing setup. A', B' and C' depict the evolution of the characteristic temperatures (cold element, hot element and an arbitrary point within the sample) over time for setups A, B and C, respectively.

As mentioned above, ice templating can shape materials for a vast array of applications. Such diversity implies that a wide variety of compounds can be shaped into macroporous foams. We will here retrace the evolution of ice templating, from an industry-oriented materials processing technique - devoted mostly to the fabrication of macroporous ceramic green bodies ${ }^{1,7,23}$ - to the fabrication of materials of increasing relevance in biological context such as macroporous gels for cell culture ${ }^{13,24}$ or cryoprotection matrices for cellular cryopreservation ${ }^{17,25-27}$. Figure 2 retraces how the composition of suspensions and/or solutions treated by ice templating has evolved from ceramics to living cells. More than a simple chronologic recital of the application or the chemical nature of the processed materials, we focus on how 
the control over the processing technique has led to the fabrication of materials whose composition is increasingly labile. Table 1 regroups some of the most relevant bibliographic references according the composition of the ice templated scaffolds and their respective application discussed on this rewiew.

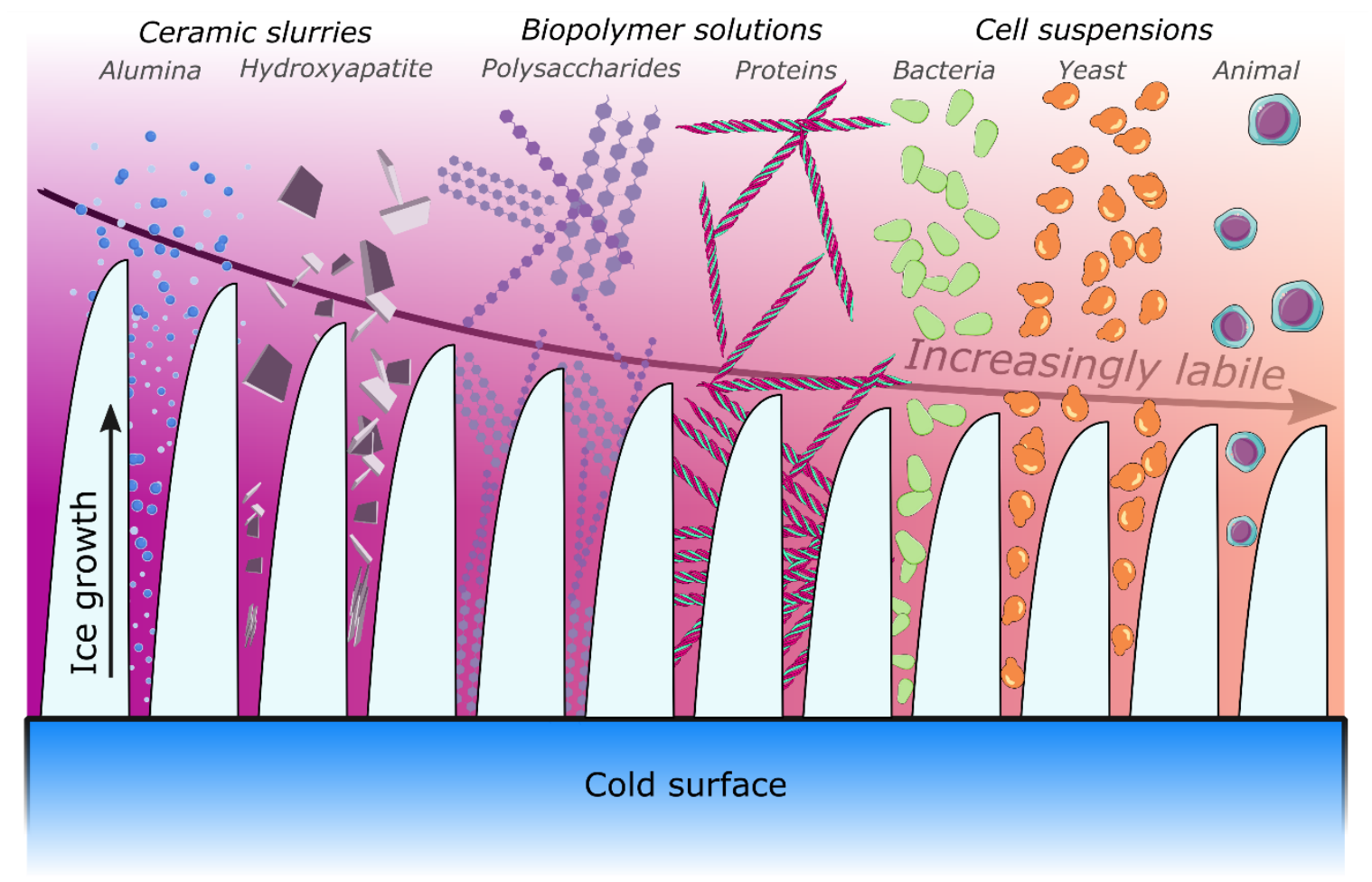

Figure 2. Ice templating has evolved from a materials processing strategy designed to shape ceramic green bodies to a technique that enables the encapsulation of increasingly labile matter. From the left to the right: ceramic slurries such as alumina or hydroxyapatite, biopolymer solutions such as polysaccharides and proteins, and cell suspensions such as bacteria, yeast cells, and animal cells are trapped in the interstitial space defined by ice crystals. The height of the ice crystals indicates the respective maturity of the materials developed: bigger crystals correspond to initial ceramics-centered research and smaller crystals to more recent materials where ice templating is used to shape materials containing biological entities. 
Table 1: Non-exhaustive summary of the main references describing ice templated materials according to the materials used and their applications, presented in this review.

\begin{tabular}{|c|c|c|c|c|c|c|}
\hline \multirow[b]{2}{*}{ Material } & \multicolumn{2}{|c|}{ Bioinspired composite materials } & \multicolumn{4}{|c|}{ Bioengineering applications } \\
\hline & bone-inspired & nacre-inspired & $\begin{array}{l}\text { bone tissue } \\
\text { engineering }\end{array}$ & $\begin{array}{c}\text { neural tissue } \\
\text { engineering }\end{array}$ & other tissues & cell encapsulation \\
\hline \multicolumn{7}{|l|}{ Ceramic slurries } \\
\hline Alumina & $\begin{array}{l}\text { Launey et al. } 2009^{28} \\
\text { Munch et al. } 2008^{29}\end{array}$ & $\begin{array}{l}\text { Wat et al. } 2019^{30} \\
\text { Garnier et al. } 2019^{31} \\
\text { Guo et al. } 2018^{32} \\
\text { Bouville et al. } 2014^{33}\end{array}$ & & & & \\
\hline Hydroxyapatite & $\begin{array}{l}\text { Mallick } 2009^{23} \\
\text { Deville et al. } 2006^{34}\end{array}$ & Deville et al., $2006^{35}$ & $\begin{array}{l}\text { Jung et al. } 2019^{36} \\
\text { Song et al. } 2018^{37} \\
\text { Yang et al. } 2017^{38} \\
\text { Liu et al. } 2016^{39} \\
\text { Bai et al. } 2015^{40} \\
\text { Cheng et al. } 2015^{41} \\
\text { Zhang et al. } 2014^{42}\end{array}$ & & & \\
\hline \multicolumn{7}{|l|}{ Biopolymers } \\
\hline Gelatine-based & & & Arabi et al. $2018^{43}$ & $\begin{array}{l}\text { Ghorbani et al. } 2020^{44} \text {, } \\
\text { Ghorbani et al. } 2017^{45}\end{array}$ & & \\
\hline Chitosan & & & & $\begin{array}{l}\text { Yin et al. 2018 } \\
\text { Francis et al. } 2013^{24} \text {, } \\
\text { Riblett et al. } 2012^{16}\end{array}$ & & \\
\hline Collagen & & & $\begin{array}{l}\text { Semyari et al. } 2018^{47} \\
\text { Clearfield et al. } 2017^{48} \\
\text { Xia et al. } 2013^{49 *}\end{array}$ & & $\begin{array}{l}\text { Rieu et al. } 2019^{13} \\
\text { Campbell et al. } 2017^{50} \\
\text { Davidenko et al. } 2010^{51}\end{array}$ & \\
\hline Silk Fibroin & & & $\begin{array}{l}\text { Maleki et al. } 2019^{52 *} \\
\text { Yang et al. } 2017^{53 *} \\
\text { Mandal et al. } 2009^{54}\end{array}$ & & $\begin{array}{l}\text { Wang et al. } 2019^{55 *} \\
\text { Lee et al. } 2016^{56 *}\end{array}$ & \\
\hline Alginate & & & & & & $\begin{array}{l}\text { Qin et al. } 2020^{57} \\
\text { Christoph et al. } 2016^{17}\end{array}$ \\
\hline
\end{tabular}

* refers to in vivo implants 
Processing biomolecules using techniques that were not initially designed to do so requires a detailed analysis of the potential risks associated with denaturation and subsequent loss of functionality. In many processing strategies - such as those developed for the shaping of polymers in molten state temperature poses the highest concern, since most biomolecules degrade below the typical temperature range for thermoplastics extrusion. Such risks can, in many cases, be minimized by adjusting the processing window to meet the conditions tolerated by biomolecules, as reported for the extrusion of plant biopolymers. ${ }^{58}$ An especially difficult scenario emerges when transposing techniques that rely on the evaporation of a solvent such as spray drying. Recent results have shown that even in case where the solvent is water $\left(\mathrm{T}_{\text {vap }}=100{ }^{\circ} \mathrm{C}\right)$ and the biopolymer being processed into microparticles is type I acid soluble collagen $\left(\mathrm{T}_{\text {denat }} \cong 37{ }^{\circ} \mathrm{C}\right)$ the processing window can be adjusted to favor solvent evaporation yet prevent collagen denaturation. ${ }^{59}$ Similarly, techniques that rely on high pressure, high shear or the use of some organic solvents during the processing, risk to denature the biological moieties and require thus an important work to shift their operational window as to preserve the identity - an thus the functionality - of biomolecules.

Shaping materials in presence of living cells is far more delicate and, as a consequence, less common. In such case, finding the processing window becomes less intuitive than in the previous examples since it extends to a cumulative set of narrow conditions that are vital to preserve the integrity and activity of living cells. Simultaneously controlling parameters such as the $\mathrm{pH}$ of the suspension medium, electrical field, $\mathrm{O}_{2}$ partial pressure, presence of cytotoxic compounds, osmotic pressure, temperature, mechanical stress or the ability to create a sterile environment imposes heavy constraints to most materials processing techniques. In this context, the number of available processing techniques drops dramatically. The most relevant example is that of $3 \mathrm{D}$ printing, that has progressively evolved from additive fabrication of mostly polymeric materials to a technique that shapes biopolymers in physiological conditions. Such success was rapidly extended to print bioinks - cells suspended in biopolymer solutions - to fabricate pre-cellularized 
constructs. ${ }^{60}$ Also electrospinning, a technique where high direct current voltage is the driving force to shape materials into fibers, has been adapted to shape materials containing living cells. ${ }^{61}$

Most of the previously discussed techniques, are able to shape biopolymers (and some of them can actually transform viable cell suspensions) into useful biomaterials. Most of the equipment required for these processing techniques is commercially available as are formulations such as bioinks, which enable easy preparation of biomaterials from of the shelf ingredients. Moreover, employing techniques such as fiber extrusion, electrospinning or 3D bioprinting provides high degree of control over the samples geometry and size. If a precise geometrical control over the samples is required for a given application then these techniques, and in particular those relying on additive fabrication should be favored. Conversely, if a macroporous porous structure is required but the control over the materials' characteristic dimensions is less strict, then ice templating provides an extremely versatile tool. The average pore size can be easily modulated by varying ice front velocity in ice templated scaffolds, however, the polydispersity of the distribution is likely to stay relatively high. ${ }^{62}$ The equipment required for the successful shaping of materials based on controlled ice growth is simple and inexpensive to build. In addition, it can be easily scaled to dimensions that may prove difficult to achieve using techniques such as electrospinning or aerosol basedtechniques. Another important advantage of ice templating is the use of low temperatures and low shear during the whole fabrication process. This aspects strongly limits the thermal denaturation that may occur with other techniques.

In the following sections we describe how ice templating has followed the previous examples. Its processing window has been narrowed down to a range that seems now compatible with the fabrication of biomaterials from increasingly sensitive biomolecules and, more recently, living cells.

\section{Bioinspired composite materials obtained by ice templating}

The morphological resemblance between materials obtained by ice templating and some of the most elusive structures in biological materials has triggered a major turn in the history of freezing as a path 
to fabricate materials. From the distance now, and apart from the inherent thrill in reproducing the morphologies of natural materials, it seems that the combination of high toughness, high strength and controlled crack propagation obtained for ceramic materials obtained via ice templating were central arguments in further developing the technique. In addition, the technique enabled the local assembly of organic binders and inorganic particles into highly concentrated composite systems, reminiscent of natural materials such as nacre and bone, whose properties were similarly desirable in ceramics materials. Bone and nacre are the paradigmatic examples of natural materials in which the precise hierarchical architecture and composition result in structures that are particularly efficient in terms of their mechanical behavior. In some cases these materials are more efficient than the sum of their parts, challenging the upper bound set by the rule of mixtures. ${ }^{63}$

\subsection{Nacre-inspired materials}

Nacre is composed of an ordered assembly of circa $95 \%(\mathrm{v} / \mathrm{v})$ aragonite platelets separated by an organic phase composed of chitin and proteins such as fibroin and lustrin. Despite its brick and mortar architectural simplicity, nacre's superior fracture toughness and flexural strength has been essential to unravel highly efficient mechanical reinforcement principles. ${ }^{64-66} \mathrm{~A}$ variety of materials processing techniques aimed at reproducing nacre's native structures has been proposed, ranging from layer-by-layer techniques ${ }^{67,68}$ to electrophoretic deposition of clay tactoids intercalated with polymers ${ }^{69}$. Opposite from the previous techniques, which are more appropriate for the fabrication of $2 \mathrm{D}$ materials, ice templating allows to fabricate materials in 3D. Upon the formation of ice crystals, particles are segregated from the ice front, resulting in a local increase in concentration of particles and solutes initially in suspension or solution. In the case of highly anisotropic lamellar particles suspended in the initial slurry, the concentration increase due to exclusion from the ice fraction may lead to an effective alignment between particles. Many of the examples of nacre-mimicking materials produced by ice templating - such as $\mathrm{Al}_{2} \mathrm{O}_{3}{ }^{4,28,30-33,70}$, clay platelets $^{71}$ or graphene oxide ${ }^{72-74}$ - take advantage of such phenomenon to define a structured lamellar morphology. Subsequent infiltration with another phase contributes to the final nacre-like brick-and-mortar 
architecture. Another advantage inherent to the technique lies in the ability to obtain extremely high particle volume fractions even from relatively diluted initial slurries. Deville et al. ${ }^{35}$ have reported nacre-like morphologies produced both from alumina or hydroxyapatite (Hap) that reached mineral volume fractions comparable to some hard biological tissues: up to $45 \%(\mathrm{v} / \mathrm{v}) \mathrm{Al}_{2} \mathrm{O}_{3}$ or $60 \%(\mathrm{v} / \mathrm{v})$ Hap. The obtained alumina scaffolds were reminiscent of nacre, in particular due to their high inorganic volume fraction and periodical layered structures obtained. Adjusting the ice front velocity resulted in controlled change in wall thickness between $\sim 1$ and $\sim 100 \mu \mathrm{m}$, evidencing the role of this simple parameter in tailoring the final architecture of the obtained materials. Upon infiltration with an epoxy resin to reproduce the binding role of the organic phase, both alumina and Hap composites revealed interesting crack deflection properties. ${ }^{35}$

One of the lessons that have emerged from the mechanics of nacre is that the interfacial properties play a major role in improving toughness. Features such as roughness, bridges and nano-asperities are critical in maximizing the mechanical response of final ice templating nacre-like materials. Ice dendrites formed during ice templating were found to promote surface roughening similar to the bridges found in nacre. ${ }^{35}$ Favoring the formation of surface roughness would dramatically increase the strength and fracture toughness of final composites from 400 to $600 \mathrm{MPa}$ and 5.5 to $10 \mathrm{MPa} \cdot \mathrm{m}^{1 / 2}$ respectively. In other examples the bridges between alumina and PMMA [poly (methyl methacrylate)] phase were, along with the interfacial roughness considered helpful for efficient energy dissipation and high friction sliding between ceramic and polymer phase, contributing to the final toughening mechanism of nacre-like composites. ${ }^{4}$ Garnier et al. ${ }^{31}$ fabricated alumina-based brick-and-mortar composites by ice templating Ni-coated alumina platelets and $\mathrm{NiO}$ nano-particles (Figure 3A). Sintering process under reductive atmosphere transformed $\mathrm{NiO}$ to metallic Ni particles that served as bridges and asperities (Figure 3B), which were thought to be responsible for the lower crack driving force and high crack face friction. This approach was furthered by Bouville et al. ${ }^{33}$ who, using only brittle components, achieved nacre-like materials from alumina platelets (500 nm thickness, $7 \mu \mathrm{m}$ diameter, equivalent to aragonite platelets in nacre) associated with alumina nanoparticles $(100 \mathrm{~nm})$ and silica-calcia colloidal suspension $(20 \mathrm{~nm})$ between platelets. After pressing and 
sintering, the resultant nacre-like alumina materials exhibited high flexural strength (470 MPa) and fracture toughness (21 MPa.m $\left.{ }^{1 / 2}\right)$, corresponding to a $600 \%$ increase compared to the reference alumina. The coalignment of alumina platelets obtained during ice templating, together with the bridges, nano-asperities and pores located in the interfaces between platelets, resulted in crack deflection behavior characteristic of nacreous materials.
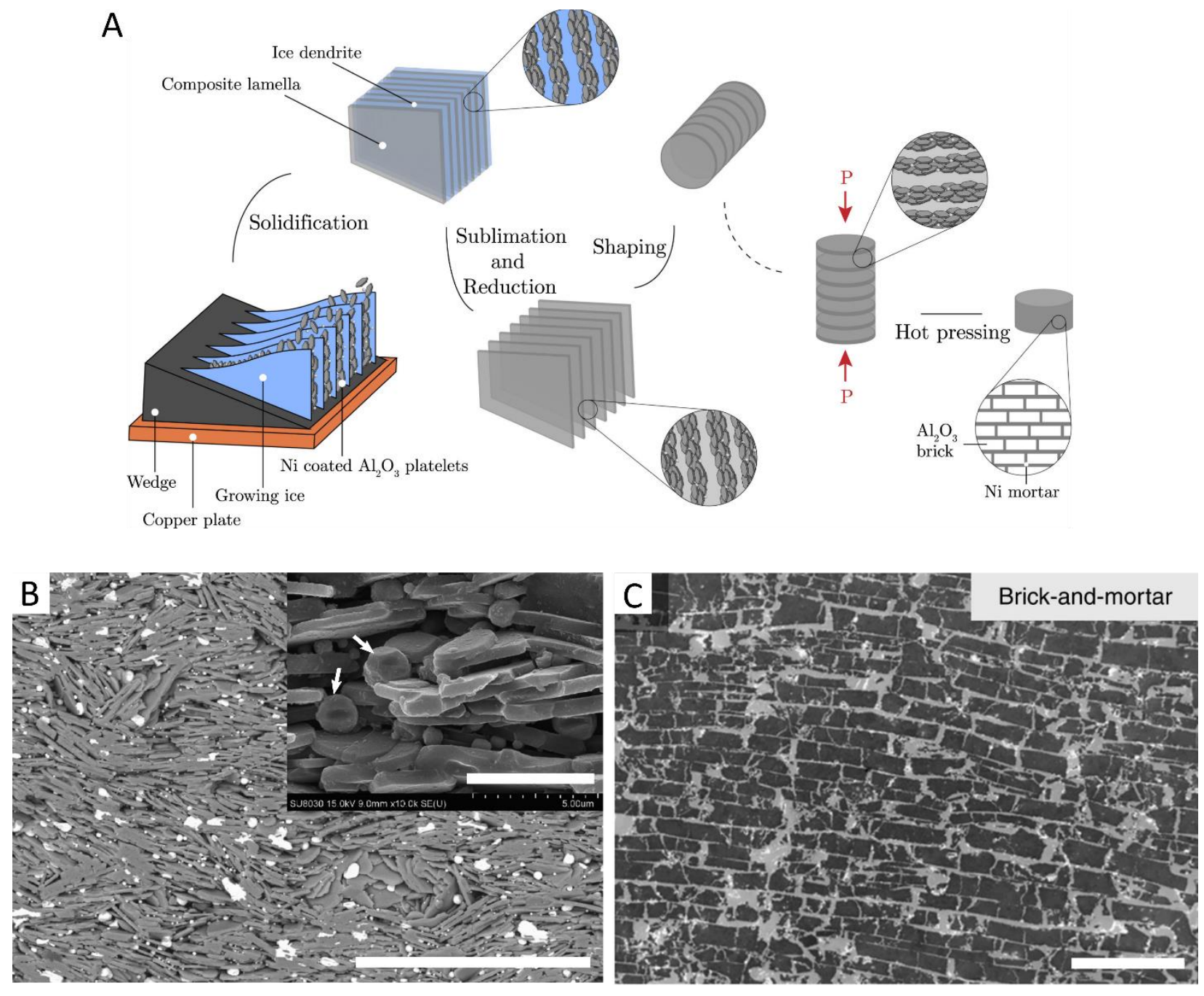

Figure 3 Structure and properties of nacre-inspired scaffolds via ice templating. (A) Processing scheme for brick-and-mortar alumina composites. (B) SEM images of alumina composites (grey) with 10 vol.\% Ni particles (white) located between platelets. White arrows in inset, indicating $\mathrm{Ni}$ particles in high magnification. Scale bar is $50 \mu \mathrm{m}$ for main image and $5 \mu \mathrm{m}$ for inset. (C) SEM picture of brick-and-mortar- 
like alumina/BMG (bulk metallic glass) alloy fabricated by four main steps: 1) ice templating of alumina particles; 2) sintering and infiltration with paraffin wax; 3) high-pressure pressing and sintering; 4) infiltration of BMG phase into alumina scaffold. Scale bar is $100 \mu \mathrm{m}$. Images A and B were reprinted from ref $^{31}$, Copyright (2018), with permission from Elsevier. Image C was adapted from ref ${ }^{30}$.

Beyond the morphological features of platelets and their interfaces, also the chemical composition at those interfaces plays an important role in the toughness of nacre-like composites. Grafting of methacrylate group on the alumina surface before infiltration of PMMA was suggested as a strategy to maximize the interaction between the inorganic and the organic phases. ${ }^{4}$ This approach resulted in covalent bonding between ceramic and polymer phases and, as a consequence, in a more cohesive brick-and-mortar system. Non-grafted composites showed delamination, while flatter and denser surfaces were observed for grafted composites. The interfacial covalent bonding increased strength and crack initiation toughness, especially for brick-and-mortar composites due to toughening mechanisms of the "pull-out" between bricks and friction sliding. Wat et al. ${ }^{30}$ applied a pressureless, fast melt-infiltration with Zr-based bulk metallic glass (BMG) to alumina matrix fabricated by bidirectional freezing with a $20^{\circ}$ wedge. The resultant alumina/BMG composites exhibited nacre-like brick-and-mortar structures with high alumina fraction of $\sim 80$ vol.\% (Figure 3C). In their report, infiltration temperature was explored as a strategy to modulate the interfacial reaction between alumina and BMG phases, which could further tune its mechanical properties. Mao et al. $^{75}$ applied a consecutive assembly-and-mineralization process to fabricate nacre-inspired aragonite/chitin/silk fibroin composites, drawing the final materials one step closer to nacre's native composition. Laminated chitosan scaffold was transformed into $\beta$-chitin via unidirectional freezing followed by acetylation. The mineralization process was subsequently achieved by continuous flow of aqueous $\mathrm{Ca}\left(\mathrm{HCO}_{3}\right)_{2}$ solution in the presence of polyacrylic acid and $\mathrm{Mg}^{2+}$ using a circulating system. The following infiltration of silk fibroin (SF) and hot pressing yielded a final composite containing approximately $91 \%(\mathrm{v} / \mathrm{v})$ aragonite, comparable to mineral volume fraction found in natural nacre. The 
synthetic composite also shared other morphological features with the natural counterpart such as laminated structure and surface roughness. Nacre-like tile aragonite platelet layers with 2 to $4 \mu \mathrm{m}$ thickness was alternated by 100 to $150 \mathrm{~nm}$ thick organic layers, leading to similar crack extension resistance curves compared to natural nacre.

Nacre-inspired materials have been prepared via ice templating using different types of molecular, macromolecular and particle building blocks, resulting in materials with mechanical properties comparable to those of the biological tissues. Beyond the composition of the different composite materials - that ranges from metal matrices to highly sensitive biopolymers - the remarkable mechanics, in particular fracture toughness, rely on reproducing the architectural principles found in nacre. Ice templating alone or coupled to other processing routes has enabled to produce materials where an effective $2 \mathrm{D}$ arrangement of particles was compatible with the fabrication of bulk, 3D objects. In this sense, ice templating represents a quite unique combination of the top-down and bottom-up fabrication strategies. It allows to precisely control the macroscopic dimensions of the produced materials by a top-down approach while promoting a bottom-up assembly of the particles in suspension. The resulting materials show thus order at multiple scales, ranging from the co-alignment of anisotropic nanoparticles to the controlled macroporosity determined by ice growth.

\subsection{Bone-inspired materials}

Similarly to nacre, the unique mechanical properties of bone have long puzzled materials scientists. Both natural materials share a common aspect. They are hybrid materials composed of high volume fraction of high aspect ratio inorganic particles assembled together by a biopolymer-rich phase. In bone, these components, non-stoichiometric apatite and collagen, make up circa $95 \%$ (w/w) of its dry weight. ${ }^{76}$ As with materials mimicking nacre, the pursuit to reproduce bone's mechanical performance has been mostly focused in reproducing the materials' architecture rather than its composition. There are some general similarities between both natural materials but the hierarchical complexity of bone remains unique. Recent reports define nine hierarchical levels between whole bone as an organ and its individual components. ${ }^{77}$ If 
in nacre-inspired materials the "brick and mortar" structure seemed accessible by ice templating followed by compression, the same cannot be said for bone. However, materials prepared by ice templating do present a macroporous morphology that seems to recapitulate the macroscopic architecture of cancellous or trabecular - bone. Figure 4A depicts the cross-section of a human proximal femur obtained by Computed Tomography (CT) scanning and Figure 4B shows the macroporous structure of a pectin foam obtained by ice templating. Beyond the pores' characteristic dimensions which are notably different, a first comparison between these $2 \mathrm{D}$ representations seems to indicate some degree of similarity in the architecture of both materials. However, a deeper look into the macroscopic morphology of cancellous bone reveals that the roughly analogous structures are, indeed, less similar than expected. Trabecular bone morphology has been shown to evolve with age, gender and site in the body ${ }^{78}$, indicating a degree of specificity of the tissue that is not intuitive for the non-specialist. As an indication to its complexity we can take the diversity of histomorphometric indicators for trabecular bone. Indeed, a standard description of this tissue takes into account, among others, parameters such as the trabecular bone volume fraction, trabecular number, trabecular separation and trabecular thickness. ${ }^{79}$ These descriptors are often accompanied by empirical observation parameters that describe the prevalence of plate-like or rod-like structures. ${ }^{78}$ While some degree of control over the pores' architecture is possible in ice templating - by using different additives during freezing, different ice front velocities, different suspended solid fraction or by the available knowledge in ice physics ${ }^{80}$ - the differences in pore morphology that can be obtained in ice templating are still dramatically far from reproducing bone's sophisticated trabecular structure. 

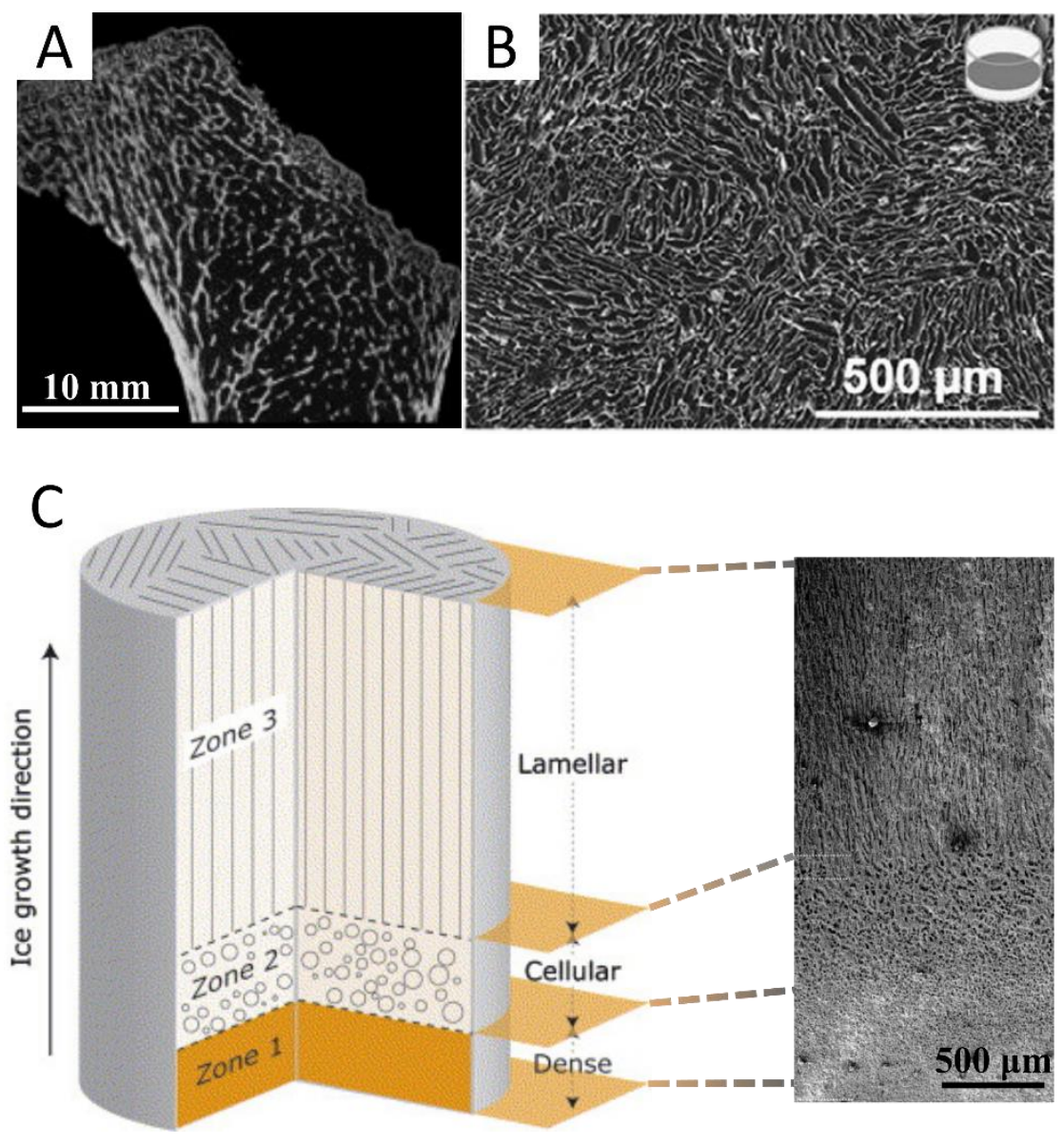

Figure 4 Morphology of bone-inspired materials obtained by ice templating. (A) High-resolution CT crosssection image of human (2 to 3 years old) proximal femur. (B) SEM cross-section image of porous pectin foam $\left(20\right.$ g.L $\left.\mathrm{L}^{-1}\right)$. (C) Hierarchical structures of ice templated Hap scaffold along ice growth direction. (A) Reprinted from ref ${ }^{81}$, Copyright (2006), with permission from Elsevier. (B) Reprinted from ref $^{3}$, Copyright (2018), with permission from Elsevier. (C) Reprinted from ref $^{34}$, Copyright (2006), with permission from Elsevier.

In the literature, multiple attempts at reproducing bone-like materials by ice templating or by associating ice templating with 3D printing are reported. ${ }^{34,36,37,48,82}$ The structures obtained via ice templating are often presented as parallel pores formed by ice growth. These parallel structures are, however, a partial view of the morphology of the materials obtained during ice templating. The initial freezing zone, 
in contact with the cold interface, is normally characterized by a dense phase that freezes suddenly due to water supercooling. Above this dense zone a cellular pore zone is formed and further away from the cold interface the lamellar co-aligned pore zone is found. Figure 4C illustrates the different morphologies arising from the different freezing regimes that occur during ice templating. Some of the most interesting materials obtained by ice templating devoted to mimicking bone or bone-related tissues have explored such gradient structure rather than reproducing the "foam-like" architecture of cancellous bone - whose structure could be most likely obtained with "standard" freezing techniques. ${ }^{83}$ Hap-based materials exhibiting gradient porosity that were fabricated by ice templating featured a sequence of different pore structures along the thermal gradient axis (Figure 4C). From the bottom to the top the materials displayed a dense zone close to the cold finger, a middle zone with interconnected cellular structures and an upper zone with lamellar channels. $^{34,82}$ These structures could provide interesting experimental models to describe cortical-tocancellous transition zones in bone as well as the property gradients found in cartilage-related materials. ${ }^{48,84}$

Despite its name, compact bone tissue is a porous material. Similarly to trabecular bone, also the porosity plays a major role in the tissue functionality. Compact bone is characterized by two families of pores within the osteon or haversian system. One corresponds to the lacunar-canicular system, that features lacunae that host osteocyte bodies, with diameter of around $10 \mu \mathrm{m}$, connected by a network of canaliculi with diameters of around $500 \mathrm{~nm}$ responsible for the connection between adjacent lacunae. ${ }^{85}$ The second family of pores corresponds to the interconnected haversian and Volkmann's canals with diameters of around $50 \mu \mathrm{m}$ that host the vascular system of compact bone. ${ }^{86}$ Both families of pores are critical for the cortical bone function and any attempt at reproducing this tissue should take into account the reproduction of these structures. In order to achieve the specific pore structure of cortical bone, ice templating has been coupled with additive manufacturing processes to produce scaffolds with dual porosity. ${ }^{36,37,82}$ For instance, a negative mold composed of acrylonitrile butadiene styrene (ABS) was designed with orthogonally distributed rods via 3D printing. ${ }^{82}$ Subsequently, the 3D printed mold filled with chitosan-alginate solution was directionally ice templated, freeze-dried, cross-linked with $\mathrm{CaCl}_{2}$ and immersed in chloroform enabling 
mold removal to obtain the final dual pore structures. While the pore dimensions obtained were significantly larger that the characteristic porosity in compact bone $\left(\phi_{\text {small }}=300 \mu \mathrm{m}\right.$ and $\left.\phi_{\text {large }}=3 \mathrm{~mm}\right)$ the obtained materials did show dramatically higher wicking rate in both $0.1 \%$ Safranin O aqueous solution and mice blood. The excellent fluid uptake properties of this hierarchically porous scaffold was thought to be more likely to promote the cell penetration and cell seeding in both 3D cell culture and in vivo implant.

To the ability of ice-templating to shape complex porous systems that may be relevant as bone substitutes, adds the fact that the technique is particularly suitable to shape the individual components found in bone, since type I collagen is water soluble - provided the $\mathrm{pH}$ is low enough - and stable Hap slurries can be easily prepared. Reproducing some of bone's morphological aspects using apatite and collagen could answer to an increasing demand of materials that may act as efficient scaffolds in bone tissue engineering. It could also cope with the everlasting bottleneck of reaching concentrations (both mineral fraction and absolute collagen concentration) that are physiologically relevant but difficult to attain under most processing techniques.

\section{Ice templated scaffolds for bioengineering applications}

As seen above, ice templating has opened a new pathway to assemble in an effective manner inorganic particles and organic binders in order to mimic natural materials, based on previous experience in shaping ceramic green bodies. The materials discussed previously, nacre and bone, are heavily mineralized. Regardless of the mineralization degree, achieving a cohesive material from fully formed inorganic particles using ice templating usually requires an organic binding phase (there are exceptions to this rule based on all-inorganic materials but they are beyond the scope of this work). This phase should be soluble in the chosen solvent - water in the cases discussed in this chapter - and provide a cohesive interface to hold the inorganic particles together. Among the molecules used as binders, water-soluble biopolymers such alginate, pectin, chitosan, collagen, gelatin or cellulose derivatives, among others, have been extensively used. ${ }^{22}$ These water-soluble macromolecules are particularly interesting candidates for the development of freeze-casted biomaterials since they are abundant and present low immunogenicity. 
As discussed above, there is a growing body of evidence suggesting that, beyond the specific cell interactions with a given biomaterial, the response of adherent cells to materials depends strongly on local environment cues such as pore geometry ${ }^{87,88}$ or local substrate elastic moduli ${ }^{89,90}$. In this sense, shaping techniques such as ice templating that enable to control the porosity and the local rigidity of biomaterials may provide excellent candidates as platforms for in vitro 3D cell culture ${ }^{91}$ as well as future in vivo tissue engineering applications. In addition, the inherent porosity of ice templated materials simplifies one of the key bottlenecks in designing biomaterials, the diffusion limit for oxygen and nutrients that hinders the full colonization of bulk hydrogels. ${ }^{92,93}$ The following subsections address the different levers available to design ice templated materials that are suited for 3D cell culture and tissue engineering.

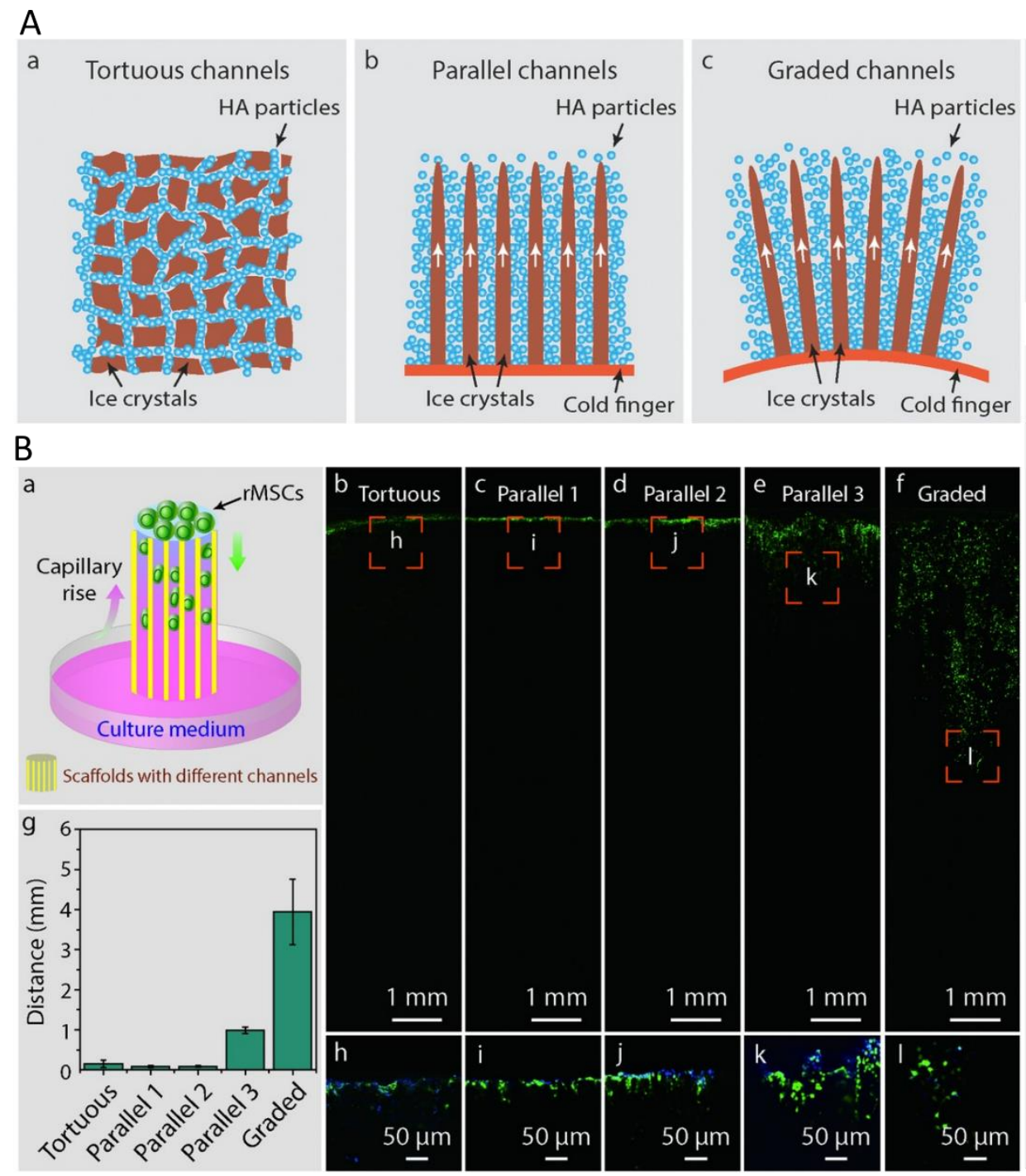


Figure 5 (A) Illustration of different microstructures of ice templated Hap scaffolds with $a$ tortuous, $b$ parallel, and $c$ graded channels. (B) rMSCs (rat mesenchymal stem cells) penetration behavior in different scaffolds after 5 hours' culture: $a$ schematic illustration of cells penetration; $b$-f fluorescence images of 4'6-diamidino-2'-phenylindole (DAPI) stained rMSCs via confocal microscopy. $b$ cell penetration in tortuous scaffolds; $c$-e. cell penetration in parallel scaffolds made at $-170,-100$, and $-50{ }^{\circ} \mathrm{C}$, respectively; $f$ cell penetration in graded scaffolds; $g$ statistical summary of cell penetration distance for different scaffolds shown in $b-f . h-l$ are high-magnification images from the parts indicated by the squares in $b-f$, respectively,. (A-B) Adapted from ref ${ }^{94}$.

\subsection{D cell culture}

The promise of physiological relevance inherent to 3D cell culture systems is strongly linked to the control over the architecture of biomaterials. ${ }^{95}$ In this context, ice templating presents an advantage among other biofabrication techniques, since it enables to create oriented pores of controllable dimensions from biopolymer solutions. Moreover, ice templating achieves this at low temperatures which limits thermal denaturation as compared to most processing techniques. This aspect is particularly relevant to shape heatlabile proteins prone to denaturation such as collagen whose importance in cell culture is paramount. ${ }^{13,96,97}$ Another interesting aspect that is inherent to ice templating is the ability to reveal the porosity of the material without the use of leaching agents such as a second solvent. Different levers can be used to tune the suitability of a macroporous material to 3D cell culture, as discussed elsewhere. ${ }^{91}$ These levers can be split into those that relate to the composition of the materials and those that relate to the process. The growth of ice causes the solutes to progressively segregate into the interstitial space defined by the newly formed crystals, because the solubility of most molecular and ionic species in ice is negligible. ${ }^{98,99}$ As a consequence, the composition of the initial solution before freezing defines the composition of the obtained macroporous material. Moreover, the composition of the solutions also modifies the viscosity of the liquid medium which modulates ice growth. 
Here we will discuss mainly two groups of levers readily available for the new ice templating user: i) the thermal gradient, such as the target temperature, the freezing rate or ice front velocity, and ii) solute effects, including the nature and concentration of the solutes. Such factors are essential to fine tune the microstructure of final matrices and thus to approach as much as possible the architecture of the target tissue.

Target temperature - It is now well established that the shape and size of pores of ice templated scaffolds can be modulated by the freezing gradient. Various authors have explored the impact of materials for 3D cell culture obtained by ice templating using different thermal gradients. For the majority of such examples the thermal gradient is defined by the gap between the sample initial temperature (often room temperature) and the target temperature of the system (freezer, cold bath, etc...). The thermal gradient will be defined by the sample volume and geometry coupled with the absolute difference between the sample temperature and the target temperature. While this approach is particularly easy to implement it provides little control over the actual gradient endured by the samples since a simple variation in sample volume or sample geometry will dramatically affect the local thermal gradients. In spite of the poor control, many works have proceeded this way to template 3D cell culture scaffolds. Amyloid-based scaffolds obtained by ice templating suspensions of amyloid fibrils (cross-linked with butanetetracarboxylic acid) at -20 and $196{ }^{\circ} \mathrm{C}$ (noted amyloid-20 and amyloid-196, respectively) exhibited different microstructure. The cellularlike morphology of amyloid-20 provided higher elastic moduli than the sheet-like morphology of amyloid196. However, the two scaffolds provided comparable viability of Caco-2 (human epithelial colorectal adenocarcinoma) cells. ${ }^{100}$ If little effect was observed on the cell culture in the case of Caco-2 cells on amyloid based-scaffolds, the topography has proven critical to determine the cell culture suitability of other ice templated 3D cell culture systems. In a study aiming to design cardiac patches based on ice templated $\mathrm{SF} /$ gelatin scaffolds, the freezing temperature was indeed a key factor. ${ }^{101}$ The scaffolds obtained at $-20^{\circ} \mathrm{C}$ exhibited isotropic morphology, whereas aligned pores were observed for scaffolds made at -30 and $-80^{\circ} \mathrm{C}$. These temperatures also resulted in smaller pores. After 2 weeks of porcine MSCs culture, the cells in the 
unidirectional scaffolds were aligned, guided by the scaffolds' pores. In contrast, the cells cultured in the isotropic scaffolds presented random adhesion without covering the whole sample volume. Also, in bonemimicking materials temperature played an important role in cell colonization. Using Hap slurry suspended in a mixture of different water-soluble polymers (sodium polyacrylate, polyethylene glycol, and polyethyloxazoline), Yang et al. ${ }^{94}$ fabricated ice templated scaffolds at different freezing temperatures (-50, -100 , and $-170{ }^{\circ} \mathrm{C}$ ) (Figure $5 \mathrm{Ab}$ ), followed by lyophilization and sintering. When decreasing the freezing temperature from -50 to $-170{ }^{\circ} \mathrm{C}$, the characteristic pore sizes also decreased from $\sim 8$ to $\sim 2 \mu \mathrm{m}$. Scaffolds fabricated at $-50{ }^{\circ} \mathrm{C}$ (Figure 5Be,k) led to a faster migration of rat mesenchymal stem cells (rMSCs) than in those made at $-100{ }^{\circ} \mathrm{C}$ (Figure $\left.5 \mathrm{Bd}, \mathrm{j}\right)$ and $-170{ }^{\circ} \mathrm{C}$ (Figure 5Bc,i). Apart from pore size, also the pore volume fraction and the pores' interconnectivity define the cellular behavior within porous scaffolds. Mandal et al. ${ }^{54}$ obtained scaffolds with different pore sizes and porosity by freezing SF solutions (ranging from 2 to 6 wt. \%) at $-20,-80$, and $-196^{\circ} \mathrm{C}$. The decreased freezing temperature resulted in increased pore volume fraction and decreased pore size, irrespective of the SF concentration. Upon seeding normal human dermal fibroblasts (NHDFs) at the center of the scaffolds extensive migration occurred in the scaffold fabricated at $-196{ }^{\circ} \mathrm{C}$ (pore size of $80-100 \mu \mathrm{m}$ and porosity of $96 \pm 4.1 \%$ ) compared to the one fabricated at $-20{ }^{\circ} \mathrm{C}$ (pore size of $200-250 \mu \mathrm{m}$ and porosity of $86 \pm 5.8 \%$ ). These results highlight the role of the thermal boundaries in controlling cell migration and colonization of macroporous scaffolds.

Freezing rate and ice front velocity - The growth rate of ice crystals determines many of the pores' attributes in ice templating. The two most direct ways to control the porosity are thus to adjust either the cold element cooling rate or the ice front velocity. From an experimental standpoint these are very different parameters to control. They demand radically different setups (c.f. Figure 1) but their final purpose is similar, to provide some degree of kinetic control over the structuration induced by ice formation. Increased freezing rate generally results in lower pore section area which could impede cell migration. The threshold between facilitated and hindered cell migration in the macroporous scaffolds depends however on the pores' characteristic size and on cell type size. ${ }^{91}$ Meurice et al. ${ }^{102}$ obtained $\beta$-TCP (tricalcium phosphate) scaffolds 
with tubular interconnected elliptical pores, whose average large and small axis decreased from 209 to 13 $\mu \mathrm{m}$ and from 41 to $6 \mu \mathrm{m}$ when the freezing rate increased from 1 to $20{ }^{\circ} \mathrm{C} \cdot \mathrm{min}^{-1}$, respectively. MG-63 osteoblastic cells were only able to migrate into the scaffolds having pores larger than $100 \mu \mathrm{m}$. Cells penetrated $\sim 250 \mu \mathrm{m}$ into the tubular structure obtained at $1{ }^{\circ} \mathrm{C} \cdot \mathrm{min}^{-1}$, whereas no invasion took place up to 7 days' culture in scaffolds prepared at $20{ }^{\circ} \mathrm{C} \cdot \mathrm{min}^{-1}$. Besides defining the pore geometry and thus the conditions for cell migration, freezing rate also plays a role in swelling and degradation properties of the constructs that are central to cell colonization and survival. Recently, olibanum-collagen-gelatin scaffolds (OCG) cross-linked with glutaraldehyde were reported as suitable macroporous materials for neural tissue regeneration. ${ }^{44} \mathrm{~A}$ small increase in freezing rate from 1 to $3{ }^{\circ} \mathrm{C} \cdot \mathrm{min}^{-1}$, imposed a decrease in pore size from $\sim 126$ to $\sim 93 \mu \mathrm{m}$ while compressive strength increased from $\sim 3.5$ to $\sim 9.0 \mathrm{kPa}$, probably ascribed to the increased wall thickness and density. Moreover, results showed a higher water uptake ratio (1131 $\pm 35 \%$ vs $1057 \pm 31 \%)$ after incubating for $24 \mathrm{~h}$ and a higher degradation rate $(\sim 57 \%$ vs $\sim 45 \%)$ for OCG1 vs OCG3. Regarding their biocompatibility, although both scaffolds supported rat bone marrow stromal cells (rBMSCs) proliferation, OCG1 performed better than OCG3 in terms of cells migration and proliferation rate, due to its larger pores.

Scaffold composition - How to define the composition of ice templated scaffolds for 3D cell culture? Two criteria seem inevitable. The first relies on a formulation that is suitable for the process of ice templating, i.e. that segregates into a part of solidified solvent and a part of enriched solute that retains its morphology upon solvent removal. The second criteria relates to the suitability of the solute-rich phase as a scaffold to host cells. Here, criteria such as the solute's toxicity but also the local mechanical properties are central. 3D cell cultures developed using ice templating have explored the intersection between these two criteria to develop macroporous scaffolds. As mentioned earlier, achieving biomaterials whose morphology is inspired by bone's ultrastructure can be attempted using ice templating. Hap, ${ }^{37,94,103-107}$ one of the main components of bone, is consequently holding a dominant place in the fabrication of scaffolds for bone tissue engineering applications. Hap scaffolds were obtained through the use of electric field 
assisted ice templating. ${ }^{104}$ Using $\mathrm{H}_{2} \mathrm{O}_{2}$ as pore-forming agent resulted in both lamellar and spherical pores in the scaffold. When the electric field intensity increased from 0 to $90 \mathrm{kV} \cdot \mathrm{m}^{-1}$, the average diameters of the lamellar and spherical pores increased from 460 to $810 \mu \mathrm{m}$ and from 320 to $420 \mu \mathrm{m}$, respectively, due to the limited growth rate of ice crystals induced by the electric field. Osteosarcoma cells cultured in these scaffolds, presented at first a filamentous and then an elongated morphology, which suggested, according to the authors, the scaffolds' suitability as a 3D culture platform. Cell adhesion was observed in a greater extent for the scaffold prepared with high electric field intensity, pointing out the crucial role of pore size for efficient cell colonization. Apart from the microstructure, the mechanical, and biological properties of bone biomimetic scaffolds, the liquid transport properties are also important factors to promote nutrients exchange. This effect was studied by Bai et al. ${ }^{107}$ in ice templated Hap scaffold with graded lamellar pores, obtained by radial freezing using a copper rod in the center of a plastic mold. The width between lamellae changed gradually from $\sim 4.5$ at the "tip" to $11.8 \mu \mathrm{m}$ at the "base", where the tip is at the center of the scaffold (where the copper rod was placed) and the base is the edge (where the border of the plastic mold is found), respectively. Interestingly, a piece of a dry Hap scaffold, when its base was in contact with a rMSCs suspension, presented the most efficient cell self-seeding effect. Because of the capillary effect, this orientation allowed for the cells' penetration all along the sample, with the cells aligned within the graded lamellar channels. The same group further confirmed these results by comparing ice templated Hap scaffolds with a) tortuous, b) parallel, and c) graded channels in terms of cell migration ${ }^{94}$ (Figure 5A). The previously reported graded scaffolds promoted a better migration of rMSCs in their channels, when cells were seeded on top (Figure 5B). Therefore, the capillary effect in the graded scaffolds plays an important role to the faster exchange of metabolic products of cells and their surrounding nutrients but also as a tool to promote faster colonization of the cells in the initial seeding moments. These results reinforce the significance of the scaffolds structural characteristics for their efficient use in $3 \mathrm{D}$ tissue engineering applications. 
Collagens, are the most abundant component of the ECM (extracellular matrix) in connective tissues of mammals ranging from bone (as previously mentioned) to softer tissues such as tendon, skin or cornea. Such widespread distribution makes of collagen the protein of choice for the development of 3D biomaterials as in vitro models. The main difficulty in handling collagen based materials structured by ice templating relies on their stability. In fact collagen (and in particular type I collagen) require stabilization to retain the shape and structural integrity imposed by freezing. Two main strategies have been proposed to ensure the stability of freeze-casted collagen materials: chemical crosslinking and fibrillogenesis. Most examples available in the literature rely on crosslinking, which produces collagen foams ${ }^{108}$. Ice templated, freeze-dried, cross-linked collagen-hyaluronic acid (HA) composite constructs were reported as scaffolds for adipose tissue engineering towards a 3D in vitro model of the mammary gland. ${ }^{51}$ Two different concentrations of HA were used, 7.5 and 15 wt. \%. With the addition of 15 wt. \% HA, Young's modulus and collapse plateau modulus of the final composite in the hydrated state were increased from $\sim 4.26$ to $~$ $6.73 \mathrm{kPa}$ and from $\sim 495$ to $\sim 625 \mathrm{~Pa}$, compared with pure collagen matrix, respectively. This scaffold was also found to better support 3T3-L1 murine pre-adipocytes proliferation and differentiation after culturing for 8 days. The other strategy available to stabilize collagen matrices requires fibrillogenesis, an important factor for the successful establishment of collagen-based biomimetic models that ensure their unique mechanical properties, essential for cell adhesion and proliferation. Although collagen is widely used as the starting material in biofabrication approaches, the induction of collagen fibrillogenesis, without disturbing the given structure of a scaffold, remains an important challenge that has only recently been tackled. ${ }^{13}$ The ability to stabilize collagen matrices without imposing a chemical crosslinking step was achieved by topotactic fibrillogenesis that allows for ice thawing and simultaneous $\mathrm{pH}$ variation to induce fibrillogenesis. The topotactic process in ice templated collagen scaffolds took place with the help of ammonia vapors. In contact with ice, ammonia vapors gradually lowered the melting point of ice crystals and simultaneously induced collagen pre-fibrillogenesis, without damaging the anisotropic structure obtained by ice templating (Figure 6A). The obtained self-standing fibrillar collagen matrices exhibited two levels of structural organization, an increasing macroporosity along the freezing direction, and the presence of regular parallel 
micro-ridges on the walls of the lamellar pores. The obtained scaffolds in wet state showed unprecedented Young's modulus $(33 \pm 12 \mathrm{kPa}$ ) for pure collagen hydrated macroporous scaffolds. The in vitro 3D culture of NHDFs revealed cell migration into the scaffolds along their lamellar pores (Figure 6B) and better cell adherence when compared with the colonization of cross-linked scaffolds. Similar results were obtained when $\mathrm{C} 2 \mathrm{C} 12$ cells (murine myoblasts) were cultured, while a limited differentiation to myotubes was also observed.

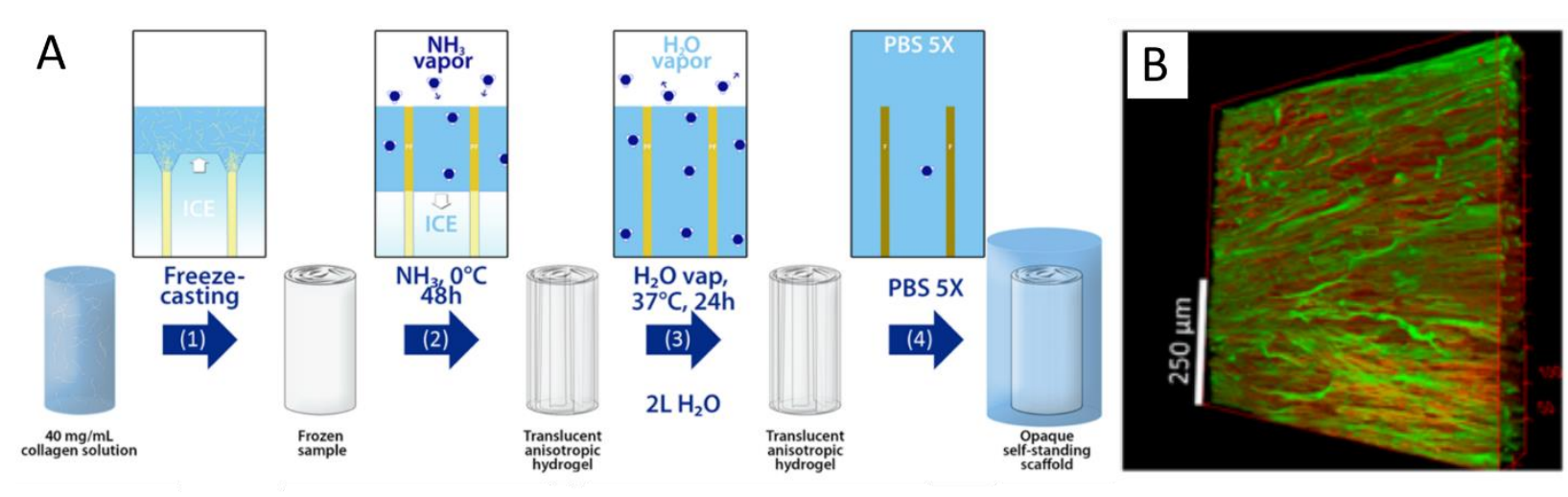

Figure 6 (A) Collagen topotactic fibrillogenesis approach for ice templated scaffolds using ammonia vapors. (B) SHG (Second Harmonic Generation) of 3D reconstruction of NHDFs on fibrillar collagen scaffold after culturing for 3 weeks. (Red, collagen SHG signal; green, actin). (A-B) Adapted with permission from ref ${ }^{13}$. Copyright (2019) American Chemical Society.

The use of in vitro 3D tumour models to understand the interactions between cancer cells and their surrounding microenvironment, is a biomedical issue that could be tackled by a precise structuration of the ECM through ice templating. Biomimetic materials are currently used in an effort to engineer the 3D cell microenvironment. ${ }^{109}$ Collagen is a protein that strongly influences cancer cell behaviour through a variety of signalling pathways. ${ }^{110}$ To further describe these interactions Campbell et al. ${ }^{50}$ fabricated radially anisotropic cross-linked collagen scaffolds for invasion studies of breast cancer cell lines. An enhanced migration was observed for the invasive cancer cell line MDA-MB-231 into anisotropic constructs 
compared with isotropic collagen scaffolds. Moreover, a 1/10\% serum gradient could further improve cells migration into anisotropic collagen constructs. When invasive MDA-MB-468 cells were treated with epidermal growth factor, thus acquiring a mesenchymal phenotype, they migrated for a longer distance into anisotropic scaffolds, confirming the scaffolds ability to distinguish invasive phenotypes.

Apart from Hap and collagen, other natural materials such as gelatin, ${ }^{111,112} \mathrm{SF},{ }^{53,101}$ and chitosan ${ }^{16,24}$ have been turned into scaffolds suitable for in vitro tissue engineering purposes by ice templating. Gelatin, derived from the partial hydrolysis of native collagen is a low cost product. It has been widely used in tissue engineering due to its hydrophilicity, low antigenicity, and potential collagen-related functions, like the RGD sequence, enabling better cell adhesion, differentiation, and proliferation. ${ }^{45,111,113}$ Ice templated, freeze-dried, cross-linked gelatin-based scaffolds were analyzed by microCT, in order to investigate the structural features of this type of scaffolds. ${ }^{111}$ Also here, the dependence of structural properties with ice templating parameters has been evidenced; highly directional structure was achieved at $-30{ }^{\circ} \mathrm{C}$, while the addition of hydrochloric acid in the initial gelatin solution doubled the pore diameter compared to pure gelatin matrices. In terms of cell culture, the larger pores resulted in significantly higher cell seeding efficiency of porcine chondrocytes. Gelatin was also used as an additive to improve the hydrophilicity of unidirectional PLGA ice templated constructs, for artificial peripheral nerve regeneration. ${ }^{114}$ Compared to pure PLGA scaffolds, composite PLGA-gelatin ones, showed increased pore size, slightly decreased compressive strength, and enhanced swelling ratio, biodegradation rate, and drug release levels. Although both PLGA and PLGA-gelatin constructs could support growth of L929 fibroblast cells, cells showed a better spreading into PLGA-gelatin matrices. Improved differentiation of P19 embryonic carcinoma cells with the addition of retinoic acid as a neural growth factor in PLGA-gelatin scaffolds further proved its potential for peripheral nerve regeneration. The same group further investigated gelatin-based freeze-casted scaffolds for bone tissue engineering. ${ }^{112}$

Silk fibroin, a natural polymer extracted from Bombyx mori cocoons, has also been selected as a starting material for ice templated scaffolds because of its versatility, biocompatibility, tunable mechanical 
properties and biodegradability. ${ }^{115-117}$ As we described earlier, SF combined with gelatin was used for the elaboration of anisotropic constructs. ${ }^{101}$ The addition of gelatin resulted in smaller pore size, higher water retention, and lower scaffold shrinkage after methanol treatment. In addition, gelatin promoted better porcine MSCs proliferation and viability. Silk fibroin hydrated flat films were converted to 3D-like scaffolds thanks to the topography induced by ice templating followed by freeze-drying. ${ }^{53}$ Evenly distributed nanoridges were observed on the films with mean length and mean spacing between them of $\sim 932 \mathrm{~nm}$ and $\sim 640 \mathrm{~nm}$, respectively. hMSCs were successfully cultured on both flat and nanoridged films, but on the latter, they adopted an elongated morphology. Gene expression analysis for osteogenic specific markers showed significantly higher levels on nanoridged films, indicating that the sole nanotopography of SF films could induce the differentiation of hMSCs into osteoblasts without added supplements.

Chitosan, a linear polysaccharide, has also been used as a base material for the elaboration of biomaterials for tissue engineering applications. Francis et al. ${ }^{24}$ fabricated macroporous, highly aligned chitosan-alginate scaffolds by ice templating at $1{ }^{\circ} \mathrm{C} \cdot \mathrm{min}^{-1}$, for neural tissue engineering. Freeze-dried, cross-linked samples were then submitted to surface modification with a polycation (poly-L-ornithine or poly-L-lysine) and/or laminin. Modified scaffolds promoted a significantly longer neurite growth of embryonic chick dorsal root ganglia (DRGs) compared to non-coated scaffolds. In addition, the coated scaffolds could direct the alignment of neurite growth along the ice templating direction. Further studies of the same group resulted in chitosan constructs combining aligned lamellae with a distance of $71 \pm 22.1 \mu \mathrm{m}$ between them and uniform ridges located on the lamellae. ${ }^{118}$ Confocal microscopy showed an excellent neurite alignment after seeding of DRGs on laminin-coated chitosan scaffolds. Further 2D culture of DRGs on single laminin-coated lamellae extracted from the 3D constructs, revealed that ridges linearly aligned $62.4 \%$ of growing neurites presenting an angular orientation variations smaller than $\pm 10^{\circ}$ compared to that of the ridges (defined as $0^{\circ}$ ).

Solute concentration - The solute concentration for the fabrication of ice templated scaffolds suitable for 3D cell culture has also a key role in their structural properties and mechanical behavior. More 
specifically, an increased solute concentration (both for ceramics ${ }^{102,119}$ and macromolecules ${ }^{54,100,120}$ ) results in the reduction of pore size and porosity, the increase of density and the improvement of mechanical properties. An indicative example can be found at a previously mentioned study, concerning SF ice templated scaffolds, where solutions of 2,4 , and 6 wt. \% concentrations were used. ${ }^{54}$ The comparison between pore size at the same freezing temperature, showed indeed that increasing SF concentration from 2 to 4 , and $6 \mathrm{wt} . \%$, led to decreased pore size, from $200-250$ to $100-150$, and to $75-100 \mu \mathrm{m}$, and porosity, from $86 \pm 5.8$ to $79 \pm 4.6$, and $74 \pm 2.3 \%$ respectively. These results limited the cell culture experiments to the 2 wt. \% products. The amyloid-20 4 wt. \% discussed above, favored a better HT29 (human colorectal adenocarcinoma monolayer) cell growth than the 1 wt. \% amyloid-20 and -196 scaffolds. ${ }^{100}$ Moreover, increasing the concentration, an increasing cell survival was observed only in amyloid-20, indicating that appropriate scaffold pore sizes for HT29 cells were maintained at every concentration in these samples. The impact of solute concentration was also studied by Rowland et al. ${ }^{121}$ who fabricated ice templated scaffolds in shapes of disks and hemispheres, with uniform or aligned pores, starting from porcine de-cellularized cartilage-derived matrix (CDM). As CDM concentration was increasing from 7 to $11 \mathrm{wt}$. $\%$ pore size and porosity decreased, while compressive modulus dramatically increased. The pores of the uniform constructs were visibly smaller, in contrast to the large grooves present in those with aligned pores, thus promoting MSCs infiltration. In addition, after chondrogenic culture, higher cell infiltration was found in the $11 \mathrm{wt}$ \% CDM scaffolds compared to that of $7 \mathrm{wt}$ \%. Furthermore, although the compressive modulus of the uniform scaffold was higher than that of the aligned one, both 11 wt. \% CDM scaffolds, resisted cell-mediated contraction and their compressive moduli were decreased after chondrogenic culturing for 28 days. On the contrary, 7 wt. \% CDM scaffolds suffered from highest contraction and their compressive moduli were increased. Further analysis revealed that the $11 \mathrm{wt}$ \% CDM hemisphere scaffold could not only prevent cell-mediated contraction, but also facilitated cells infiltration, which in turn promoted cartilaginous matrix deposition. 
Other approaches to the elaboration of ice templated 3D cell culture scaffolds have been proposed. In particular, the fabrication of electrically conductive 3D scaffolds such as PEDOT:PSS (Poly(3,4ethylenedioxythiophene):poly(styrenesulfonate)) has shown the potential to modulate the conformation of fibronectin adsorbed onto the surface of the ice templated foams, by the application of an oxidizing or reducing electric potential. ${ }^{122}$ This electrochemical stimulation of fibronectin-coated PEDOT:PSS scaffolds determined the adhesion of 3T3-L1 cells as well as the secretion of vascular endothelial growth factor (VEGF).

All the aforementioned studies clearly demonstrate the flexibility provided by the ice templating technique, leading to a large spectrum of biomaterials suitable for 3D cell culture applications; on one hand, by tuning freezing parameters and, on the other hand, by choosing the appropriate solute (and solute concentration), structural features and mechanical properties of ice templated scaffolds can be further improved and optimized. The cell colonization of optimized scaffolds offers multiple possibilities in the field of biomedical applications, so that ice templated scaffolds could serve as biomimetic models to elucidate cell behavior and their interactions with the surrounding environment in both physiological and pathologic conditions. Moreover, interaction of cells with the biomaterials themselves, should be evaluated prior to in vivo implantation studies.

\subsection{In vivo implantation of ice templated materials}

Regardless of the merits of any cell culture system, the transposition between in vitro culture to in vivo integration is not trivial. The inherent difficulties are linked to the performance of each system but also depend on the ability to access to in vivo testing facilities, on ethical committees' approval and on effective collaborative links with surgeons. The history of ice-templating, as a materials processing technique solidly anchored in the ceramics community, has seldom produced the conditions for those interactions to be widespread. As a consequence, the research output drops dramatically when looking for the results of ice templated 3D scaffolds tested in vivo as compared to 3D cell culture in vitro. Tissue engineering materials devoted to bone $\mathrm{e}^{49,53,103,120,123,124}$, nerve $\mathrm{u}^{46}$, $\operatorname{skin}^{125}$ and vascular grafts ${ }^{126,127}$ have been attempted via ice 
templating with composition ranging from ceramics, to natural and synthetic polymers, as well as hybrids. Appropriate microstructures, mechanical properties, and bioactivity are necessary for in vivo implantations but are not sufficient. Practical criteria such as ease of handling in the surgical block, ability to sterilize using standard medical equipment or the shelf-life of the 3D scaffolds prior to implantation pose major hurdles for the effective transposition of materials useful in 3D cell cultures to in vivo setting.

The scaffolds' microstructure and mechanical properties are important parameters not only for in vitro applications but for in vivo implantation as well, as shown in the literature through various examples. An ice templated chitosan conduit was successfully tested for peripheral nerve repair. ${ }^{46}$ The application of two opposite thermal gradients during the freezing process resulted in scaffolds consisting of a doublelayered highly-aligned porous structure, with suitable mechanical properties for in vivo testing. The conduit was able to bridge $10 \mathrm{~mm}$ sciatic nerve defects in rat models at 12 weeks post-implantation, while it favored the vascularization of its lumen. The structure of recently reported SF/collagen composite scaffolds for osteochondral tissue remodeling, had an important role on cell behavior in vivo. ${ }^{124}$ Three different scaffolds were elaborated with random, axially aligned, and radially aligned pores by ice templating and temperature gradient-guided thermally-induced phase separation. Morphology analysis of cross-sections revealed significantly smaller pore sizes for radially $(68.0 \pm 20.3 \mu \mathrm{m})$ and axially aligned $(69.9 \pm 24.1 \mu \mathrm{m})$ scaffolds compared to those of the random scaffold. At 18 weeks post-implantation in rabbits with osteochondral defects, axially and radially aligned scaffolds, especially the latter, favored cell migration and infiltration, resulting in faster cartilage regeneration rate.

The combination of ice templating with other biofabrication techniques, like electrospinning, could further tune pore characteristics of the final products, providing benefits for both in vitro and in vivo cell behavior. Lee et al. performed cold-plate electrospinning with PCL and SF nanoparticles (SP) aiming at the fabrication of macroporous matrices for artificial dermis applications (Figure 7A-B). ${ }^{125}$ The presence of SP in PCL nanofibers endowed the composites with enhanced interconnected pore size, porosity, and hydrophilicity. The scaffolds were implanted into full-thickness skin defects in rat wound models. Their 
structural and physicochemical properties resulted in more efficient cell infiltration and collagen deposition, leading in turn to faster wound healing rate compared to that of pure PCL matrices 20 days postimplantation. PCL/SP composites showed comparable wound healing rate to the commercial Matriderm ${ }^{\circledR}$ collagen artificial dermis, while their sufficient structural support resulted in reduced contracture and scar formation (Figure 7C).
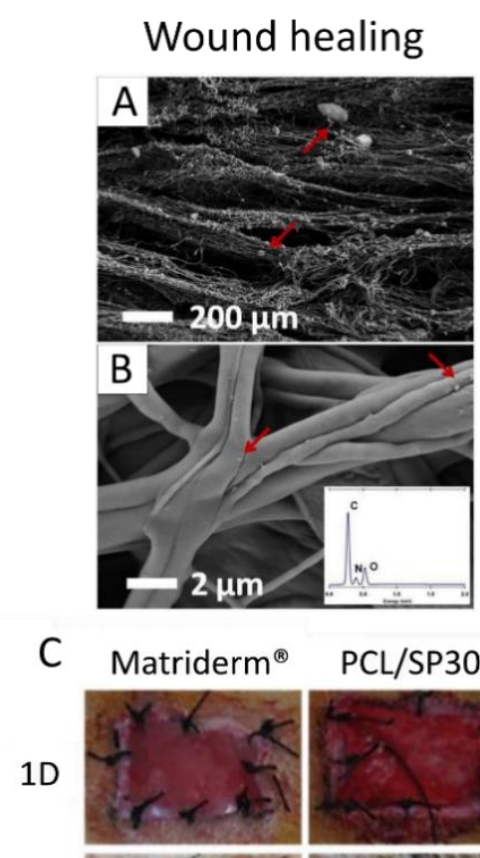

5D

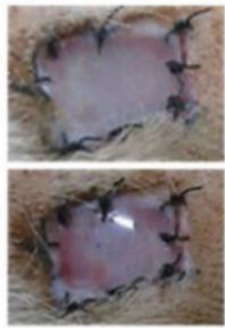

$15 \mathrm{D}$

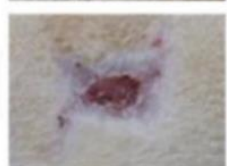

200
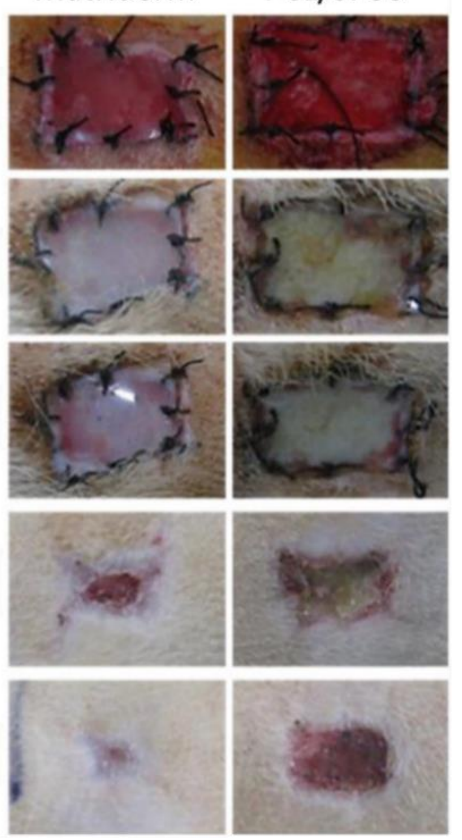
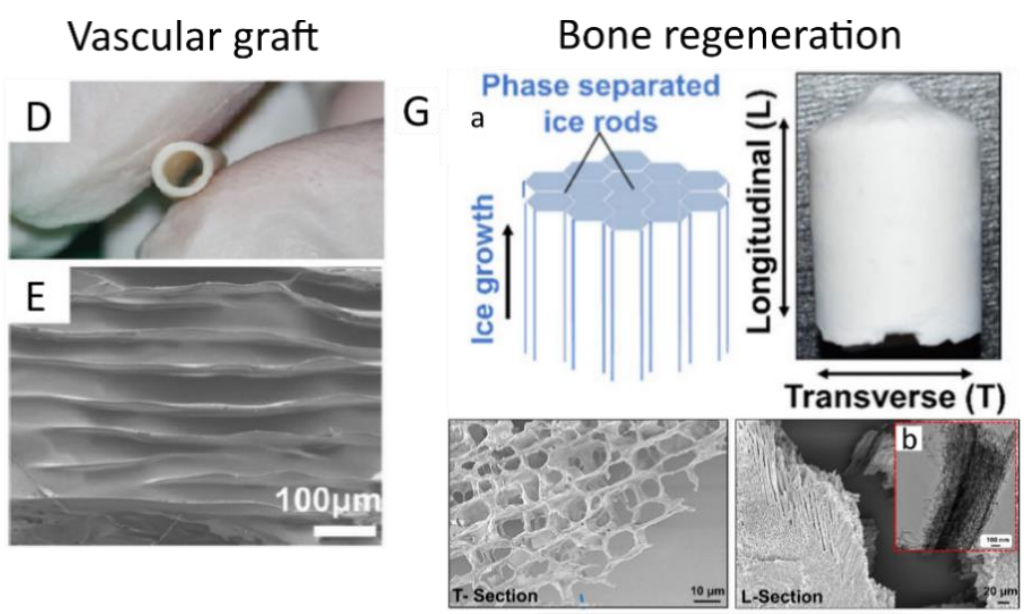

$\mathrm{F}$
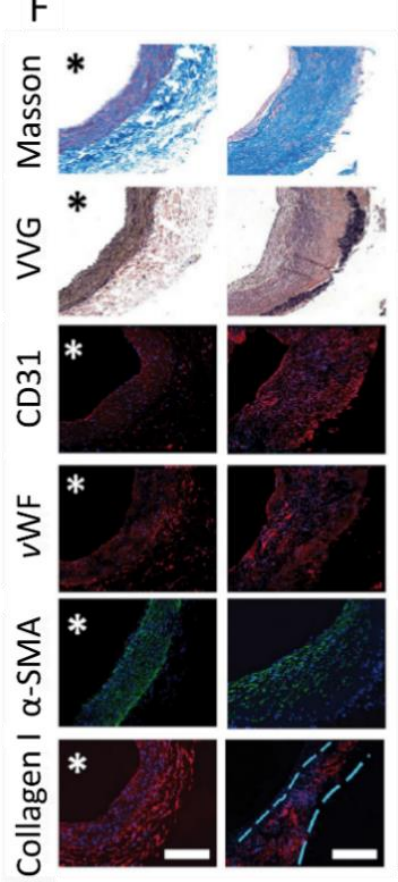

Figure 7 In vivo implantation of ice templated scaffolds. (A-B) SEM images of fibrous PCL/SP30 (PCL with 30\% SF nanoparticles) scaffold. EDS analysis is shown in the inset. (C) Macroscopic images of wound 
healing process in rat wound model with commercialized artificial dermis (Matriderm ${ }^{\circledR}$ ) and PCL/SP30 scaffold. (D) Vascular scaffold consisting of an inner layer of ice templated SF/gelatin surrounded by an electrospun poly ( $\varepsilon$-caprolactone) (PCL) outer sheath. (E) Lamellar inner surface of ice templated graft. (F) Cross-sections of lamellar $(*)$ and non-lamellar grafts with histological staining for collagen (blue) and elastin (black), and immunofluorescent staining for CD 31 (red), vWF (red), $\alpha$ - SMA (green), and collagen I (red), respectively. (G) Macroscopic and microscopic images of ice templated silica/SF scaffold with honeycomb structure. (H) Macroscopic images of the implant site of rat femur 25 days post-implantation. (A-C) Reprinted from ref ${ }^{125}$, Copyright (2016), with permission from Elsevier. (D-F) Adapted with permission from ref ${ }^{126}$. Copyright (2019) American Chemical Society. (G-H) Adapted with permission from ref ${ }^{123}$. Copyright (2019) American Chemical Society.

Ice templated scaffolds topography is also an important factor for their evaluation as suitable in vivo implants. As discussed earlier, Yang et al. ${ }^{53}$ found that the sole existence of well distributed nanoridges on a SF film induced hMSCs differentiation to osteoblasts. After one month's implantation into subcutaneous dorsum sites of rats, a higher amount of calcified tissue was formed on nanoridged films than on flat ones, while this difference was more easily observed when hMSCs were pre-seeded on the films. Besides, more organized fibrous tissues containing more collagen deposition were observed around nanoridged films than around flat films, both for pre-seeded or not films. Expression of osteopontin and osteocalcin was found at the outer surface of nanoridged films, even without seeded hMSCs. The same result confirming the formation of bone-like tissue was also observed on flat films, but only when seeded with hMSCs. Therefore, nanoridges per se on SF films could promote bone formation both in vitro and in vivo. Wang et al. ${ }^{126}$ elaborated small diameter vascular grafts composed of an electrospun PCL outer sheath and an ice templated and freeze-dried SF/gelatin inner layer (Figure 7D). The inner surface exhibited a lamellar structure with height of $10 \mu \mathrm{m}$, thickness of $200 \mathrm{~nm}$, and average gap between two lamellae of 20 $\mu \mathrm{m}$ (Figure 7E). Mechanical properties (including elastic response, burst pressure and elongation at break) 
and stability in PBS buffer of PCL-coated scaffolds were enhanced, compared to those of scaffolds without the PCL sheath. The presence of lamellae on the inner surface not only inhibited significantly the adhesion and activation of platelets, but promoted the growth and alignment of endothelial cells as well, compared to non-lamellar grafts. Furthermore, scaffolds with lamellar topography could maintain good antithrombosis properties and high blood flow within 3 months' implantation in rabbit carotid artery defect models. The well-organized elastin, collagen, and muscle fibers, as well as the expression of relative proteins on the lamellar grafts confirmed the ability of the scaffolds to conduct in situ endothelialization (Figure 7F).

The integration of bioactive additives during the preparation of starting solutions or suspensions prior to the ice templating process, can favour tissue engineering applications. As previously mentioned, bone-oriented materials hold a dominant position among in vivo implantations. This application could benefit from the introduction of bioactive compounds in the base material to promote more efficient integration and/or post-operative controlled drug release. A hybrid aerogel fabricated via ice templating, followed by supercritical drying, was recently reported, using a sol-gel assembly of organosilane (tetraethyl orthosilicate) and SF (Figure 7G). ${ }^{123}$ The silica-SF scaffold immersed in a cold bath at $-196{ }^{\circ} \mathrm{C}$ at a constant rate of $33 \mathrm{~cm} \cdot \mathrm{h}^{-1}$ exhibited micro-honeycomb hierarchical pore structures with macropore and mesopore sizes of $\sim 18 \mu \mathrm{m}$ and $\sim 17 \mathrm{~nm}$ respectively and showed the lowest bulk density $\left(\rho_{\mathrm{b}}=0.075 \mathrm{~g} \mathrm{~cm}^{-3}\right)$ and the highest Young's modulus ( $\varepsilon=7.3 \mathrm{MPa}$ ) along the freezing direction. Regarding the in vitro biological properties, this scaffold was considered as clinically implantable as it showed augmented protein adsorption, minimal effect on human red blood cells lysis, bone-like Hap crystals formation on its surface, and MG-63 osteoblasts attachment and proliferation. Macroscopic images of implants dissected 25 days post-surgery, demonstrated significant bone tissue regeneration around and inside the implants in the defect sites induced in rat models (Figure 7H). Another scaffold used for bone tissue engineering involves mineralized collagen fibers, derived from collagen and apatite (Col-Ap) suspensions in a modified simulated body fluid promoting collagen self-assembly and in situ apatite precipitation. ${ }^{49}$ These suspensions were submitted to 
either random, either unidirectional controlled freezing, leading to equiaxed and lamellar structure, respectively. By varying the initial collagen concentration $\left(1.0,2.0\right.$, and 3.0 g. $\left.\mathrm{L}^{-1}\right)$, precipitated apatite content was $\sim 54, \sim 35$ and $\sim 18 \%$ respectively (hence the scaffolds Col-Ap-54, -35 , and -18). Analyzing the equiaxed scaffolds, with the increase of apatite content, decreased average pore size and porosity were observed under the same freezing conditions. The composition of Col-Ap-35 equiaxed scaffolds with pore sizes of $\sim 82 \mu \mathrm{m}$ had greater similarity with natural bone, therefore being selected for in vivo implantation. Scaffolds loaded with murine calvarial cells (mCOBs) were implanted in cranial defects of mouse models. After 4 weeks' implantation, the defect was repaired, with more than $90 \%$ of the area filled with newly formed bone.

The examples listed above are not exhaustive. They provide however, a quick survey of the relevance of ice templated materials in in vivo settings and thus their potential to address different tissue engineering challenges. Ice templating endows scaffolds with controlled microstructures, mechanical properties and bioactivity, contributing to effective tissue regenerations upon implantation. One aspect that is worth mentioning is, for a given scaffold, the coherence between cell behavior in vitro and in vivo. Such results seem to confirm the increased physiological relevance of ice templated 3D cell culture scaffolds as suitable model to predict the cellular response in vivo.

\section{Encapsulation during ice templating in biomaterials design}

One of the key phenomena occurring during ice templating is the segregation of the solutes towards the interstitial space defined by ice crystals due to the insolubility of most molecular and ionic species in ice. ${ }^{98,99}$ The case of suspended particles is more complex and has been extensively discussed in the literature from different perspectives due to its relevance in a wide range of domains, from geophysics to biology and engineering. ${ }^{128-132}$ The fate of stable suspended particles in a given solvent when meeting an advancing freezing front can be either engulfment (into ice), rejection from the ice front or encapsulation in between 
the growing ice crystals. Many factors play a role in these different scenarios such as the ice front velocity, the particle size or the particles density among others. The relevance of such phenomena in cryobiology has been anticipated in the early 1980s with a series of groundbreaking works devoted to understand the interaction between suspended cells and moving ice fronts. ${ }^{133,134}$

The first observations of the interaction between suspended cells and moving ice fronts followed, in particular with an interest in the fate of erythrocytes during directional freezing. ${ }^{27,135,136}$ Under directional freezing, red blood cells were mostly entrapped in the interdendritic regions, especially at high ice front velocities. This results led the authors to hypothesize that, upon freezing in saline medium, high osmotic pressure due to solute concentration or the mechanical stress from the ice crystals caused cell death. ${ }^{27,137}$ Interestingly, they observed that cells were uniformly distributed and showed higher viability when glycerol was added. ${ }^{27}$ They suggested that the reason behind is that glycerol could inhibit the formation of ice crystals and reduce the mechanical stresses that cells experience. Similar effects were later observed with high concentration of trehalose ${ }^{137}$ and dimethyl sulfoxide (DMSO) ${ }^{138}$. Also sperm cells derived from different species such as donkey ${ }^{139}$, bull ${ }^{140}$, and killer whale ${ }^{141}$ have been cryoprotected with directional freezing and resulted in successful fertilization after artificial insemination. For instance, bull semen was collected from ten Holstein-Friesian bulls and protected in commercialized Berliner Cryomedium supplemented with $7 \%$ v/v glycerol via directional freezing. ${ }^{138}$ Compared with fresh sperm, thawed samples showed more than $75 \%$ viability and comparable acrosome integrity and similar sperm morphology. It was also shown that controlled ice nucleation during slow freezing is not necessary for directional freezing in view of viability and other functional analysis, which indicates that directional freezing could reduce costs and save energy during cell cryoprotection. 

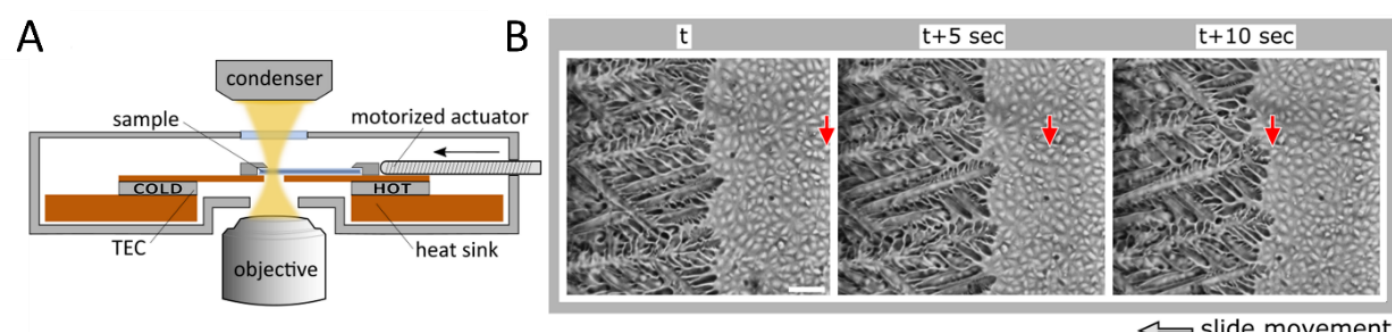

C

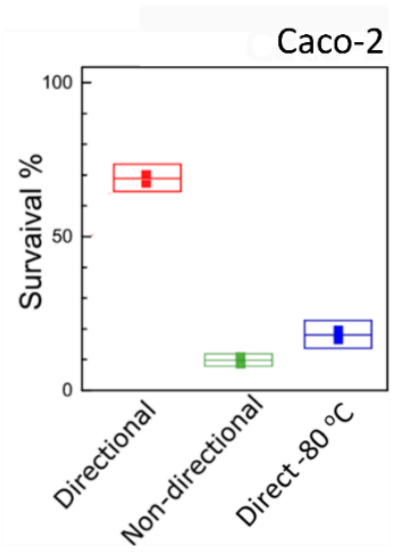

D

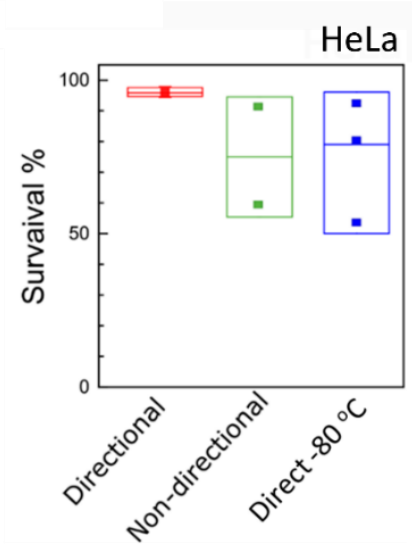

E

$\longleftarrow$ slide movement
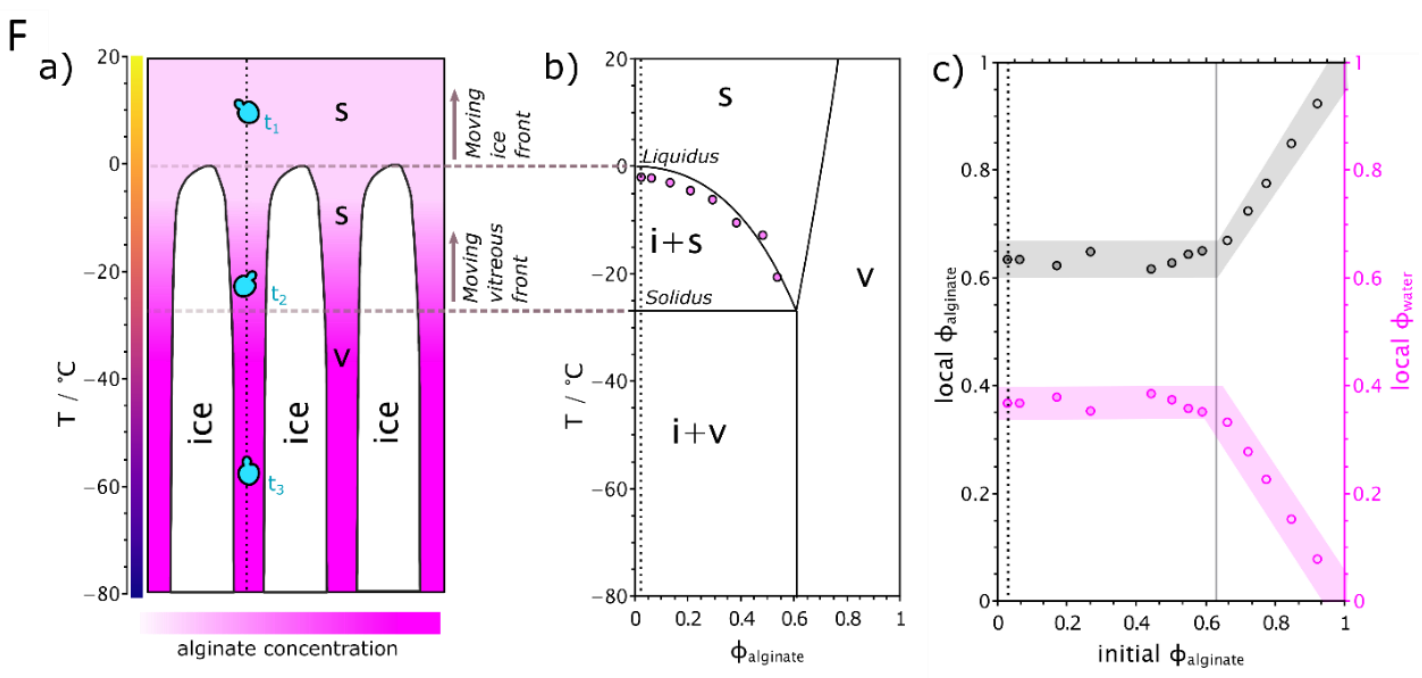

Figure 8 (A) Schematic illustration of translational cryostage. This stage is integrated with a microscope which can in situ observe freezing behavior when sample is moved by a motorized actuator from hot to cold side. (B) Representative images of ice front propagation in IEC-18 epithelial cell suspension (in 10\% DMSO). The red arrows indicate one cell gradually being frozen when sample is moved. Survival rate based on flow cytometry for Caco-2 (C) and HeLa cell (D) after combination of directional freezing and gradual cooling, non-directional gradual cooling $\left(1{ }^{\circ} \mathrm{C} \cdot \mathrm{min}^{-1}\right)$ and direct freezing at $-80{ }^{\circ} \mathrm{C}$ freezer. (E) SEM images of lamellar alginate foams with encapsulated yeast cells. (F) Directional freezing induced phase 
segregation of alginate aqueous solution. a) Scheme of ice growth and rejection of alginate and yeast cells between ice crystals. b) Phase diagram of alginate solution based on experimental crystallization temperature (magenta points) and theoretical glass transition temperature from Gordon Taylor model. c) Non-freezing water and alginate volume fraction within alginate segregated phase. $s$, alginate solution; $i$, ice phase; $v$, vitreous phase. Scale bar, $100 \mu \mathrm{m}$ (B). (A-D) Adapted from $\operatorname{ref}^{26}$. (E) Adapted from ref ${ }^{17}$. (F) Adapted from $\operatorname{ref}^{57}$.

This technique could also be applied for the cryopreservation of adherent cells, such as neuron-like cells ${ }^{142}$ and intestinal epithelium IEC-18 cells ${ }^{26}$. More specifically, Bahari et al. ${ }^{26}$ applied two-stage freezing to IEC-18 cells in the presence of DMSO: a) translational cryostage for directional freezing (Figure 8A) to approximately $-8{ }^{\circ} \mathrm{C}$ at various speeds, followed by gradual freezing to $-20{ }^{\circ} \mathrm{C}$ at $1.2{ }^{\circ} \mathrm{C} \cdot \mathrm{min}^{-1}$, and b) liquid nitrogen-cooled stage for cooling to $-80{ }^{\circ} \mathrm{C}$ at $0.5 / 1{ }^{\circ} \mathrm{C} \cdot \mathrm{min}^{-1}$. During directional freezing the increase of velocity (Figure 8B) and DMSO concentration resulted in more branches and narrower width of the ice crystals. The protocol with velocity of $30 \mu \mathrm{m} . \mathrm{s}^{-1}$ in directional freezing, liquid nitrogen gradual freezing at $0.5^{\circ} \mathrm{C} \cdot \mathrm{min}^{-1}$, and DMSO concentration more than $7.5 \%$ was able to maintain the round morphology of IEC18 cells. The same conditions were applied for the cryopreservation of HeLa and Caco2 cells. Their viability was higher when protected via directional freezing than that of samples processed either with nondirectional but controlled freezing rate, or directly in $-80{ }^{\circ} \mathrm{C}$ (Figure $\left.8 \mathrm{C}-\mathrm{D}\right)$.

Directional freezing could also promote the formation of uniform ice crystals reducing the effect of supercooling and osmotic stress on cells. Apart from cells, directional freezing has already been used for the cryopreservation of small tissues, like ovary ${ }^{143-145}$ and liver ${ }^{146}$ in the presence of cryoprotectant agents like DMSO and ethylene glycol. However, these agents could induce harmful effects to cells like decreased DNA stability, especially at high concentrations. ${ }^{147}$ 
Another alternative to reduce mechanical stress is the use of biopolymers instead of toxic cryoprotectants such as DMSO to protect cell entities via ice templating. Our group has recently proposed that alginate could be successfully applied to protect Saccharomyces cerevisiae without using any toxic chemicals. ${ }^{17}$ Mixtures of alginate and yeast cells were unidirectionally ice templated and rehydrated; cell viability was evaluated through cells' metabolic activity. The obtained results showed that yeast cells were mostly trapped into well-aligned alginate lamellae (Figure 8E) and retained their metabolic activity, thus indicating the existence of viable yeast cells in dried alginate foams. The entrapment of cells during ice growth and possible viscosity drag caused by alginate pave a way to novel cryopreservation approach via ice templating. The use of biocompatible polymers could not only alleviate the potential mechanical stress generated during freezing, but also improve entrapment efficiency within the viscous polymer phase. Recently, our team has combined the confocal microscopy setup developed by Dedovets et al. ${ }^{148}$ with alginate solution phase diagrams to describe the evolution of the polymer concentration during freezing (Figure $8 \mathrm{~F}$ ). This led to the description of alginate concentration profile during freezing. Moreover, these results demonstrate the ability to encapsulate cells in a vitreous domain, regardless of the freezing rate. This novel approach presents the advantage of regulating the growth of ice crystals and simultaneously trapping cells inside the polymer phase to achieve efficient cell protection in the absence of toxic agents.

Merging of directional freezing technology - that was known in the cryobiology domain - with the developments that rose from a different community, that of ice templating, has widened the possibility to understand the fundamental physicochemical processes endured by cells during freezing. The anisotropy of ice templating/directional freezing provides an opportunity to probe the interaction between the medium being frozen and its interaction with growing ice crystals, a feat inaccessible to a standard freezing setup. In particular, the controlled freezing environment and the possibility to integrate it into other characterization instruments has enabled to determine, for the first time, the pressure generated in between ice crystals and how it depends with the freezing rate. ${ }^{149}$ These results that directly depend on the 
intersection between directional freezing and ice templating will provide much needed insight to tackle the cryopreservation of ever more sensitive biological entities.

\section{Conclusion}

This review paper highlights some of the more recent developments in ice templating, notably its path to manipulate entities of biological origin. We describe how the quest to reproduce the mechanical performance of biomaterials such as nacre or bone has triggered the elaboration of materials suitable for cell culture that overcome many of the limitations found in other 3D cell culture systems (liquid transport, ease of fabrication and readily available parameters to modulate the porosity and mechanical properties). The parallelism observed between in vitro models elaborated using ice templating and in vivo experiments seems to indicate that ice templated materials seem particularly adapted both as cell culture models and tissue engineering applications. The ability to produce 3D cell culture models that are physiologically more relevant opens a pathway to culture cells that are currently impossible to maintain in classical cell culture systems. One of such examples is that of circulating tumor cells (CTCs). These cells are shed by solid tumors in the patients' bloodstream and are responsible for metastases formation. The establishment of long-term CTCs cultures remains a challenge of great difficulty, mainly because of their scarcity, and the specific biological interactions between them and the suitable microenvironment for their expansion, which need to be further elucidated. ${ }^{150}$

Finally, the intersection between ice templating and directional freezing - a particular freezing technology in cryobiology that shares the same basic principles - has enabled to deepen the understanding of how biological entities endure freezing before, during, and after the interaction with the freezing front. These results hold promise to minimize and/or eliminate the need for toxic cryoprotectants and widen the range of cells and tissues that can be cryopreserved. 


\section{Acknowledgement}

This work was supported by French state funds managed by the National Research Agency (ANR) through the CellsInFoams project, grant no. ANR-17-CE08-0009. KQ acknowledges funding from the China Scholarship Council, Ph.D. grant no. 201606230232. CP acknowledges funding by the Île-de-France Region through a RESPORE (Network of Excellence in Porous Solids) post-doctoral allocation.

\section{References}

$1 \quad$ S. Deville, Materials (Basel)., 2010, 3, 1913-1927.

2 M. C. Gutiérrez, M. L. Ferrer and F. Del Monte, Chem. Mater., 2008, 20, 634-648.

3 S. Christoph, A. Hamraoui, E. Bonnin, C. Garnier, T. Coradin and F. M. Fernandes, Chem. Eng. J., 2018, 350, 20-28.

4 E. Munch, M. E. Launey, D. H. Alsem, E. Saiz, A. P. Tomsia and R. O. Ritchie, Science (80-. )., 2008, 322, 1516-1520.

5 C. Huang, J. Peng, S. Wan, Y. Du, S. Dou, H. D. Wagner, A. P. Tomsia, L. Jiang and Q. Cheng, Angew. Chemie, 2019, 131, 7718-7722.

6 B. Wicklein, A. Kocjan, G. Salazar-Alvarez, F. Carosio, G. Camino, M. Antonietti and L. Bergström, Nat. Nanotechnol., 2015, 10, 277-283.

$7 \quad$ S. Deville, Adv. Eng. Mater., 2008, 10, 155-169.

8 Y. Bai, R. Liu, Y. Wang, H. Xiao, Y. Liu and G. Yuan, ACS Appl. Mater. Interfaces, 2019.

9 Y. Zhang, L. Zhang, G. Zhang and H. Li, ACS Appl. Mater. Interfaces, 2018, 10, 21565-21572.

10 Q. Wang, X. Wang, F. Wan, K. Chen, Z. Niu and J. Chen, Small, 2018, 14. 
11 M. Xie, Y. Zhang, M. J. Kraśny, C. Bowen, H. Khanbareh and N. Gathercole, Energy Environ. Sci., 2018, 11, 2919-2927.

12 Y. Zhang, J. Roscow, M. Xie and C. Bowen, J. Eur. Ceram. Soc., 2018, 38, 4203-4211.

13 C. Rieu, C. Parisi, G. Mosser, B. Haye, T. Coradin, F. M. Fernandes and L. Trichet, ACS Appl. Mater. Interfaces, 2019, 11, 14672-14683.

14 G. Nyström, W. K. Fong and R. Mezzenga, Biomacromolecules, 2017, 18, 2858-2865.

15 A. G. Guex, J. L. Puetzer, A. Armgarth, E. Littmann, E. Stavrinidou, E. P. Giannelis, G. G. Malliaras and M. M. Stevens, Acta Biomater., 2017, 62, 91-101.

16 B. W. Riblett, N. L. Francis, M. A. Wheatley and U. G. K. Wegst, Adv. Funct. Mater., 2012, 22, $4920-4923$.

17 S. Christoph, J. Kwiatoszynski, T. Coradin and F. M. Fernandes, Macromol. Biosci., 2016, 16, $182-187$.

18 M. C. Gutiérrez, Z. Y. García-Carvajal, M. Jobbágy, L. Yuste, F. Rojo, C. Abrusci, F. Catalina, F. Del Monte and M. L. Ferrer, Chem. Mater., 2007, 19, 1968-1973.

19 G. Singh and S. Soundarapandian, Ceram. Int., 2019, 45, 11633-11638.

20 L. Xie, D. Yao, Y. Xia, J. Yin, H. Liang, K. Zuo and Y. Zeng, J. Eur. Ceram. Soc., 2019, 39, 2036-2041.

21 H. Zhang, J. Long and A. I. Cooper, J. Am. Chem. Soc., 2005, 127, 13482-13483.

22 K. L. Scotti and D. C. Dunand, Prog. Mater. Sci., 2018, 94, 243-305.

23 K. K. Mallick, in Journal of the American Ceramic Society, 2009, vol. 92.

24 N. L. Francis, P. M. Hunger, A. E. Donius, B. W. Riblett, A. Zavaliangos, U. G. K. Wegst and M. A. Wheatley, J. Biomed. Mater. Res. - Part A, 2013, 101, 3493-3503. 
A. Arav and J. Saragusty, Anim. Reprod. Sci., 2016, 169, 6-13.

L. Bahari, A. Bein, V. Yashunsky and I. Braslavsky, PLoS One, 2018, 13, 1-17.

H. Ishiguro and B. Rubinsky, Cryobiology, 1994, 31, 483-500.

M. E. Launey, E. Munch, D. H. Alsem, H. B. Barth, E. Saiz, A. P. Tomsia and R. O. Ritchie, Acta Mater., 2009, 57, 2919-2932.

E. Munch, M. E. Launey, D. H. Alsem, E. Saiz, A. P. Tomsia and R. O. Ritchie, Science (80-. )., 2008, 322, 1516-1520.

A. Wat, J. I. Lee, C. W. Ryu, B. Gludovatz, J. Kim, A. P. Tomsia, T. Ishikawa, J. Schmitz, A. Meyer, M. Alfreider, D. Kiener, E. S. Park and R. O. Ritchie, Nat. Commun., 2019, 10.

M. J. Garnier and D. C. Dunand, Mater. Sci. Eng. A, 2019, 743, 190-196.

R. F. Guo, N. Guo, P. Shen, L. K. Yang and Q. C. Jiang, Mater. Sci. Eng. A, 2018, 718, 326-334.

F. Bouville, E. Maire, S. Meille, B. Van De Moortèle, A. J. Stevenson and S. Deville, Nat. Mater., $2014,13,508-514$.

34 S. Deville, E. Saiz and A. P. Tomsia, Biomaterials, 2006, 27, 5480-5489.

35 S. Deville, E. Saiz, R. K. Nalla and A. P. Tomsia, Science (80-. )., 2006, 311, 515-518.

J. Y. Jung, S. E. Naleway, Y. N. Maker, K. Y. Kang, J. Lee, J. Ha, S. S. Hur, S. Chien and J. McKittrick, ACS Biomater. Sci. Eng., 2019, 5, 2122-2133.

X. Song, H. Tetik, T. Jirakittsonthon, P. Parandoush, G. Yang, D. Lee, S. Ryu, S. Lei, M. L. Weiss and D. Lin, Adv. Eng. Mater., 2018.

D. Yang, Z. Zhao, F. Bai, S. Wang, A. P. Tomsia and H. Bai, Adv. Healthc. Mater., 2017, 6. 
$8-14$.

40 H. Bai, D. Wang, B. Delattre, W. Gao, J. De Coninck, S. Li and A. P. Tomsia, Acta Biomater., 2015, 20, 113-119.

41 Z. Cheng, K. Zhao and Z. P. Wu, Ceram. Int., 2015, 41, 8599-8604.

42 Y. Zhang, L. Chen, J. Zeng, K. Zhou and D. Zhang, Mater. Sci. Eng. C, 2014, 39, 143-149.

43 N. Arabi, A. Zamanian, S. N. Rashvand and F. Ghorbani, Macromol. Mater. Eng., 2018, 303.

44 F. Ghorbani, A. Zamanian, F. Kermanian and A. Shamoosi, Biotechnol. Prog., 2019.

45 F. Ghorbani, A. Zamanian and H. Nojehdehian, Mater. Sci. Eng. C, 2017, 77, 159-172.

46 K. Yin, P. Divakar, J. Hong, K. L. Moodie, J. M. Rosen, C. A. Sundback, M. K. Matthew and U. G. K. Wegst, in MRS Advances, Materials Research Society, 2018, vol. 3, pp. 1677-1683.

47 H. Semyari, M. Salehi, F. Taleghani, A. Ehterami, F. Bastami, T. Jalayer, H. Semyari, M. Hamed Nabavi and H. Semyari, J. Biomater. Appl., 2018, 33, 501-513.

48 D. Clearfield, A. Nguyen and M. Wei, J. Biomed. Mater. Res. - Part A, 2018, 106, 948-958.

49 Z. Xia, X. Yu, X. Jiang, H. D. Brody, D. W. Rowe and M. Wei, Acta Biomater., 2013, 9, 73087319.

50 J. J. Campbell, A. Husmann, R. D. Hume, C. J. Watson and R. E. Cameron, Biomaterials, 2017, 114, 34-43.

51 N. Davidenko, J. J. Campbell, E. S. Thian, C. J. Watson and R. E. Cameron, Acta Biomater., 2010, 6, 3957-3968.

52 H. Maleki, M. A. Shahbazi, S. Montes, S. H. Hosseini, M. R. Eskandari, S. Zaunschirm, T. Verwanger, S. Mathur, B. Milow, B. Krammer and N. Hüsing, ACS Appl. Mater. Interfaces, 2019, 11, 17256-17269. 
B. B. Mandal and S. C. Kundu, Biomaterials, 2009, 30, 2956-2965. 2019, 13, 10576-10586. Mater. Sci. Eng. C, 2016, 68, 758-767.

57 K. Qin, C. Eschenbrenner, F. Ginot, D. Dedovets, T. Coradin, S. Deville and F. M. Fernandes, J. Phys. Chem. Lett., 2020, 11, 7730-7738.

L. Chaunier, S. Guessasma, S. Belhabib, G. Della Valle, D. Lourdin and E. Leroy, Addit. Manuf., 2018, 21, 220-233.

M. Lama, F. M. Fernandes, A. Marcellan, J. Peltzer, M. Trouillas, S. Banzet, M. Grosbot, C. Sanchez, M. M. Giraud-Guille, J. J. Lataillade, B. Coulomb, C. Boissière and N. Nassif, Small, 2019, 1902224, 1-8.

60 W. Sun, B. Starly, A. C. Daly, J. A. Burdick, J. Groll, G. Skeldon, W. Shu, Y. Sakai, M. Shinohara, M. Nishikawa, J. Jang, D. W. Cho, M. Nie, S. Takeuchi, S. Ostrovidov, A. Khademhosseini, R. D. Kamm, V. Mironov, L. Moroni and I. T. Ozbolat, Biofabrication, 2020, 12, 022002 .

61 S. N. Jayasinghe, Analyst, 2013, 138, 2215.

62 S. Christoph, A. Hamraoui, E. Bonnin, C. Garnier, T. Coradin and F. M. Fernandes, Chem. Eng. $J ., 2018,350,20-28$.

63 U. G. K. Wegst, H. Bai, E. Saiz, A. P. Tomsia and R. O. Ritchie, Nat. Mater., 2015, 14, $23-36$.

64 G. M. Luz and J. F. Mano, Philos. Trans. R. Soc. A Math. Phys. Eng. Sci., 2009, 367, 1587-1605. 
H. Wei, N. Ma, F. Shi, Z. Wang and X. Zhang, Chem. Mater., 2007, 19, 1974-1978.

P. Podsiadlo, A. K. Kaushik, E. M. Arruda, A. M. Waas, B. S. Shim, J. Xu, H. Nandivada, B. G. Pumplin, J. Lahann, A. Ramamoorthy and N. A. Kotov, Science, 2007, 318, 80-83.

69 W. Lin, C. an Wang, H. Le, B. Long and Y. Huang, Mater. Sci. Eng. C, 2008, 28, 1031-1037.

P. M. Hunger, A. E. Donius and U. G. K. Wegst, J. Mech. Behav. Biomed. Mater., 2013, 19, 8793.

H. Bai, A. Polini, B. Delattre and A. P. Tomsia, Chem. Mater., 2013, 25, 4551-4556.

J. Yang, L. S. Tang, L. Bai, R. Y. Bao, Z. Liu, B. H. Xie, M. B. Yang and W. Yang, ACS Sustain. Chem. Eng., 2018, 6, 6761-6770.

O. T. Picot, V. G. Rocha, C. Ferraro, N. Ni, E. D’Elia, S. Meille, J. Chevalier, T. Saunders, T. Peijs, M. J. Reece and E. Saiz, Nat. Commun., 2017, 8.

G. Lian, C. C. Tuan, L. Li, S. Jiao, Q. Wang, K. S. Moon, D. Cui and C. P. Wong, Chem. Mater., 2016, 28, 6096-6104.

L. B. Mao, H. L. Gao, H. Bin Yao, L. Liu, H. Cölfen, G. Liu, S. M. Chen, S. K. Li, Y. X. Yan, Y. Y. Liu and S. H. Yu, Science (80-. )., 2016, 354, 107-110.

K. A. Hing, Philos. Trans. R. Soc. A Math. Phys. Eng. Sci., 2004, 362, 2821-2850.

N. Reznikov, R. Shahar and S. Weiner, Acta Biomater., 2014, 10, 3815-3826. Bone Miner. Res., 2007, 22, 817-824. 
M. Burrows, D. Liu, S. Moore and H. McKay, J. Bone Miner. Res., 2010, 25, 1423-1432.

80 S. Deville, J. Mater. Res., 2013, 28, 2202-2219.

81 T. M. Ryan and G. E. Krovitz, J. Hum. Evol., 2006, 51, 591-602.

82 S. Reed, G. Lau, B. Delattre, D. D. Lopez, A. P. Tomsia and B. M. Wu, Biofabrication, 2016, 8.

83 Y. S. Pek, S. Gao, M. S. M. Arshad, K. J. Leck and J. Y. Ying, Biomaterials, 2008, 29, 43004305.

84 Y. Kameo, N. Sakano and T. Adachi, Bone Reports, 2020, in press.

85 X. Zhou, J. E. Novotny and L. Wang, Bone, 2009, 45, 704-710.

86 S. Qiu, D. P. Fyhrie, S. Palnitkar and D. Sudhaker Rao, Anat. Rec. - Part A Discov. Mol. Cell. Evol. Biol., 2003, 272, 520-525.

87 C. M. Bidan, K. P. Kommareddy, M. Rumpler, P. Kollmannsberger, P. Fratzl and J. W. C. Dunlop, Adv. Healthc. Mater., 2013, 2, 186-194.

88 M. Rumpler, A. Woesz, J. W. C. Dunlop, J. T. van Dongen and P. Fratzl, J. R. Soc. Interface, 2008, 5, 1173-1180.

89 A. J. Engler, S. Sen, H. L. Sweeney and D. E. Discher, Cell, 2006, 126, 677-689.

90 R. N. Palchesko, K. L. Lathrop, J. L. Funderburgh and A. W. Feinberg, Sci. Rep., 2015, 5, 7955.

91 K. M. Pawelec, A. Husmann, S. M. Best and R. E. Cameron, Appl. Phys. Rev., 2014, 1.

92 L. Figueiredo, R. Pace, C. D’Arros, G. Réthoré, J. Guicheux, C. Le Visage and P. Weiss, J. Tissue Eng. Regen. Med., 2018, 12, 1238-1246.

93 J. Malda, J. Rouwkema, D. E. Martens, E. P. Le Comte, F. K. Kooy, J. Tramper, C. A. Van Blitterswijk and J. Riesle, Biotechnol. Bioeng., 2004, 86, 9-18. 
94 D. Yang, Z. Zhao, F. Bai, S. Wang, A. P. Tomsia and H. Bai, Adv. Healthc. Mater., 2017, 6.

95 E. R. Shamir and A. J. Ewald, Nat. Rev. Mol. Cell Biol., 2014, 15, 647-664.

96 A. Husmann, K. Pawelec, C. Burdett, S. Best and R. Cameron, J. Biomed. Eng. Informatics, 2015, $1,47$.

97 K. M. Pawelec, A. Husmann, S. M. Best and R. E. Cameron, J. R. Soc. Interface, 2014, 11.

98 E. Thibert and F. Dominé, J. Phys. Chem. B, 1997, 101, 3554-3565.

99 E. Thibert and F. Dominé, J. Phys. Chem. B, 1998, 102, 4432-4439.

100 G. Nyström, W. K. Fong and R. Mezzenga, Biomacromolecules, 2017, 18, 2858-2865.

101 M. C. T. Asuncion, J. C. H. Goh and S. L. Toh, Mater. Sci. Eng. C, 2016, 67, 646-656.

102 E. Meurice, F. Bouchart, J. C. Hornez, A. Leriche, D. Hautcoeur, V. Lardot, F. Cambier, M. H. Fernandes and F. Monteiro, J. Eur. Ceram. Soc., 2016, 36, 2895-2901.

103 H. Semyari, M. Salehi, F. Taleghani, A. Ehterami, F. Bastami, T. Jalayer, H. Semyari, M. Hamed Nabavi and H. Semyari, J. Biomater. Appl., 2018, 33, 501-513.

104 Z. Cheng, K. Zhao and Z. P. Wu, Ceram. Int., 2015, 41, 8599-8604.

105 J. Y. Jung, S. E. Naleway, Y. N. Maker, K. Y. Kang, J. Lee, J. Ha, S. S. Hur, S. Chien and J. McKittrick, ACS Biomater. Sci. Eng., 2019, 5, 2122-2133.

106 B. Liu, L. Chen, C. Shao, F. Zhang, K. Zhou, J. Cao and D. Zhang, Mater. Sci. Eng. C, 2016, 61, $8-14$.

107 H. Bai, D. Wang, B. Delattre, W. Gao, J. De Coninck, S. Li and A. P. Tomsia, Acta Biomater., 2015, 20, 113-119.

108 M. M. Giraud Guille, N. Nassif and F. M. Fernandes, in Materials Design Inspired by Nature: 
Function Through Inner Architecture, 2013, pp. 107-127.

109 P. Beri, B. F. Matte, L. Fattet, D. Kim, J. Yang and A. J. Engler, Nat. Rev. Mater., 2018, 3, 418430.

110 S. Xu, H. Xu, W. Wang, S. Li, H. Li, T. Li, W. Zhang, X. Yu and L. Liu, J. Transl. Med., 2019, $17,1-22$.

111 R. Zehbe, J. Goebbels, Y. Ibold, U. Gross and H. Schubert, Acta Biomater., 2010, 6, 2097-2107.

112 N. Arabi, A. Zamanian, S. N. Rashvand and F. Ghorbani, Macromol. Mater. Eng., 2018, 303.

113 S. M. Lien, L. Y. Ko and T. J. Huang, Acta Biomater., 2009, 5, 670-679.

114 F. Ghorbani, A. Zamanian and H. Nojehdehian, Mater. Sci. Eng. C, 2017, 77, 159-172.

115 M. Farokhi, F. Mottaghitalab, Y. Fatahi, A. Khademhosseini and D. L. Kaplan, Trends Biotechnol., 2018, 36, 907-922.

116 A. E. Thurber, F. G. Omenetto and D. L. Kaplan, Biomaterials, 2015, 71, 145-157.

117 Y. Wang, H. J. Kim, G. Vunjak-Novakovic and D. L. Kaplan, Biomaterials, 2006, 27, 6064-6082.

118 B. W. Riblett, N. L. Francis, M. A. Wheatley and U. G. K. Wegst, Adv. Funct. Mater., 2012, 22, 4920-4923.

119 H. Shokrollahi, F. Salimi and A. Doostmohammadi, J. Mech. Behav. Biomed. Mater., 2017, 74, $365-370$.

120 B. B. Mandal, E. S. Gil, B. Panilaitis and D. L. Kaplan, Macromol. Biosci., 2013, 13, 48-58.

121 C. R. Rowland, L. A. Colucci and F. Guilak, Biomaterials, 2016, 91, 57-72.

122 A. M. D. Wan, S. Inal, T. Williams, K. Wang, P. Leleux, L. Estevez, E. P. Giannelis, C.

Fischbach, G. G. Malliaras and D. Gourdon, J. Mater. Chem. B, 2015, 3, 5040-5048. 
123 H. Maleki, M. A. Shahbazi, S. Montes, S. H. Hosseini, M. R. Eskandari, S. Zaunschirm, T. Verwanger, S. Mathur, B. Milow, B. Krammer and N. Hüsing, ACS Appl. Mater. Interfaces, 2019, 11, 17256-17269.

124 X. Feng, P. Xu, T. Shen, Y. Zhang, J. Ye and C. Gao, J. Mater. Chem. B, 2020, 8, 391-405.

125 J. M. Lee, T. Chae, F. A. Sheikh, H. W. Ju, B. M. Moon, H. J. Park, Y. R. Park and C. H. Park, Mater. Sci. Eng. C, 2016, 68, 758-767.

126 Z. Wang, C. Liu, Y. Xiao, X. Gu, Y. Xu, N. Dong, S. Zhang, Q. Qin and J. Wang, ACS Nano, 2019, 13, 10576-10586.

127 M. F. Leong, M. Z. Rasheed, T. C. Lim and K. S. Chian, J. Biomed. Mater. Res. - Part A, 2009, 91, 231-240.

128 A. E. Corte, J. Geophys. Res., 1962, 67, 1085-1090.

129 D. Dedovets and S. Deville, J. Eur. Ceram. Soc., 2018, 38, 2687-2693.

130 U. G. K. Wegst, M. Schecter, A. E. Donius and P. M. Hunger, Philos. Trans. R. Soc. A Math. Phys. Eng. Sci., 2010, 368, 2099-2121.

131 B. Saint-Michel, M. Georgelin, S. Deville and A. Pocheau, Langmuir, 2017, 33, 5617-5627.

132 S. Deville, in Freezing Colloids: Observations, Principles, Control, and Use: Applications in Materials Science, Life Science, Earth Science, Food Science, and Engineering, Springer, Cham, 2017, pp. 91-170.

133 V. L. Bronstein, Y. A. Itkin and G. S. Ishkov, J. Cryst. Growth, 1981, 52, 345-349.

134 C. Körber, Q. Rev. Biophys., 1988, 21, 229-298.

135 B. Rubinsky and M. Ikeda, A Cryomicroscope Using Directional Solidification for the Controlled Freezing of Biological Material, 1985, vol. 22. 
136 H. Ishiguro and K. Koike, in Annals of the New York Academy of Sciences, 1998, vol. 858, pp. 235-244.

137 A. Hubel, T. B. Darr, A. Chang and J. Dantzig, Cryobiology, 2007, 55, 182-188.

138 R. Fuller and R. V. Devireddy, Int. J. Heat Mass Transf., 2008, 51, 5650-5654.

139 J. Saragusty, A. Lemma, T. B. Hildebrandt and F. Göritz, PLoS One, 2017, 12.

140 J. Saragusty, J. H. Osmers and T. B. Hildebrandt, Theriogenology, 2016, 85, 1328-1333.

141 T. R. Robeck, S. A. Gearhart, K. J. Steinman, E. Katsumata, J. D. Loureiro and J. K. O’Brien, Theriogenology, 2011, 76, 267-279.

142 M. Uemura and H. Ishiguro, Cryobiology, 2015, 70, 122-135.

143 S. Maffei, G. Pennarossa, T. A. L. Brevini, A. Arav and F. Gandolfi, Hum. Reprod., 2014, 29, $114-124$.

144 S. Maffei, M. Hanenberg, G. Pennarossa, J. R. V Silva, T. A. L. Brevini, A. Arav and F. Gandolfi, Fertil. Steril., 2013, 100, 1122-1131.

145 A. Arav, Z. Gavish, A. Elami, Y. Natan, A. Revel, S. Silber, R. G. Gosden and P. Patrizio, Reprod. Biomed. Online, 2010, 20, 48-52.

146 Z. Gavish, M. Ben-Haim and A. Arav, Rejuvenation Res., 2008, 11, 765-772.

147 B. P. Best, Rejuvenation Res., 2015, 18, 422-436.

148 D. Dedovets, C. Monteux and S. Deville, Science (80-. )., 2018, 360, 303-306.

149 N. Baccile, T. Zinn, G. P. Laurent, G. Ben Messaoud, V. Cristiglio and F. M. Fernandes, J. Phys. Chem. Lett., 2020, 1989-1997.

150 L. E. Cortés-Hernández, Z. Eslami-S and C. Alix-Panabières, Mol. Aspects Med., 2020, 72, 
100816. 